\author{
П. В. ДУРЯГИН \\ Университет Венеции Ка' Фоскари \\ (Венеция, Италия) \\ pavel.duryagin@unive.it
}

\title{
ИНТОНАЦИЯ ЧАСТНОГО ВОПРОСА В РУССКОМ ЯЗЫКЕ: ЭКСПЕРИМЕНТАЛЬНОЕ ИССЛЕДОВАНИЕ ИСТОЧНИКОВ ВАРИАТИВНОСТИ*
}

\begin{abstract}
В статье представлены результаты экспериментального исследования просодии частновопросительных предложений, проведенного на материале записей чтения диалогических текстов двадцатью носителями русского языка. Данные эксперимента в целом подтверждают имеющиеся в литературе сведения о вариативности интонационного оформления русских частных вопросов. На основе результатов инструментального анализа были выделены основные типы тональных конфигураций: три «нисходящих» контура, которые различаются наличием и характером предъядерных акцентов и соответствуют вариантам контуров ИК-2 и ИК-5, выделенных в модели Е. А. Брызгуновой, и один «восходящий» контур, который соответствует ИК-4 традиционного описания. Для каждой конфигурации акцентов была предложена предварительная дискретная фонологическая интерпретация в рамках автосегментной метрической модели интонации. В ходе эксперимента было также исследовано влияние на выбор тональной конфигурации двух факторов: типа фокуса и наличия во фразе инициальной частицы $a$. Обнаружен значимый эффект обеих переменных: если корректирующий контрастный фокус ограничивал использование контура с высоким пограничным тоном (в разной степени в зависимости от того, какое слово является носителем фокуса), то при наличии частицы $a$ участники эксперимента, напротив, значительно чаще выбирали «восходящую» конфигурацию.
\end{abstract}

Ключевые слова: фонетика, интонация, частный вопрос, вариативность, фокус

\section{1. Введение}

Внутриязыковая вариативность просодии частновопросительных предложений зафиксирована в описаниях большого количества языков [Ladd 2008: 226-230]. Одно из вероятных объяснений типологической распространенности этого явления следующее: поскольку иллокутивная цель ча-

\footnotetext{
* Статья подготовлена в рамках проекта Dipartimento di Eccellenza, осуществляемого на факультете лингвистики и сравнительной культурологии Университета Венеции Ка' Фоскари. Автор выражает глубокую благодарность анонимным рецензентам журнала за ценные советы и замечания, а также участникам эксперимента за помощь в его проведении.
}

Русский язык в научном освещении. № 1. 2021. С. 137-177. 
стного вопроса в данных языках обычно маркируется лексически и синтаксически (наличием местоименного слова и его позицией во фразе), доступные просодические средства дают говорящему возможность кодировать иные лингвистические элементы значения [Haan 2001: 116-117], в частности связанные с информационной структурой и прагматическими аспектами высказывания.

Определить характер взаимосвязи между вариантами просодического оформления частных вопросов и их функциями позволяют методы экспериментальной фонетики. Так, одним из примеров изучения прагматики интонационных средств в специальном вопросе является серия экспериментов на материале греческого языка [Gryllia et al. 2018; 2019; Baltazani et al. 2020]. Согласно данным этих исследований, в греческих частновопросительных предложениях используются две тональные конфигурации: с повышением и без повышения частоты основного тона (далее - ЧОТ) на последнем слоге фразы, которые в фонологической транскрипции GRToBI, разработанной для описания интонации греческого языка [Arvaniti, Baltazani 2005], обозначаются как $\mathrm{L}^{*}+\mathrm{H} \mathrm{L}-! \mathrm{H} \%$ и $\mathrm{L}+\mathrm{H}^{*} \mathrm{~L}-\mathrm{L} \%$ соответственно. Данные перцептивных экспериментов указывают на то, что носители греческого языка чаще воспринимают фразы, произнесенные с повышением тона на последнем слоге, как собственно вопросительные, а фразы без повышения тона, напротив, как экспрессивно окрашенные вопросы, не требующие ответа ${ }^{1}$. При этом участники эксперимента воспринимали вопросы с повышением тона на последнем слоге как более вежливые.

К проблеме вариативности обращались авторы исследований на материале германских языков, в которых частный вопрос также может оформляться как с повышением тона на последнем слоге фразы, так и с отсутствием такого движения ЧОТ. Согласно данным корпусных исследований, выбор контура в английском может быть связан с личностью говорящего [Hirschberg 1989], методом элицитации (чтение вслух или спонтанная диалогическая речь [Hirschberg 2000]), элементами информационной структуры предложения [Hedberg, Sosa 2002; Hedberg et al. 2004]. Корпусное исследование на материале нидерландского языка [Chen 2012] показало, что

\footnotetext{
${ }^{1}$ Отдельную трудность при анализе частновопросительных предложений представляет проведение границы между собственно вопросительными предложениями и прочими типами фраз (риторическими вопросами, переспросами, восклицаниями с местоименными словами). Так, авторы цитируемых исследований на материале греческого языка отмечают, что изучаемые ими вопросы хотя и не требуют ответа, не являются риторическими; к риторическим они относят только вопросы, «ответ на которые очевиден и известен как говорящему, так и слушающему» ([Baltazani et al. 2020: 61]; перевод наш. - П. Д.). В настоящей работе мы старались избегать потенциально неоднозначных контекстов и рассматривали только собственно вопросительные предложения в узком смысле, т. е. вопросы, «отражающие полную неосведомленность говорящего» [Брызгунова 1980б: 394] и предполагающие его желание получить ответ.
} 
наличие или отсутствие тонального акцента ${ }^{2}$ на вопросительном слове и следующих за ним словах может быть связано, помимо информационной структуры фразы, с тем, к какой категории относится вопросительное местоимение (слово waаrom 'почему' значительно чаще оказывалось выделено просодически, чем wat 'что'). В работе также были выделены возможные прагматические функции позиции тонального акцента во фразе, в частности выражение заинтересованности говорящего. Недавнее исследование на материале немецкого языка [Repp 2019] также демонстрирует, что частновопросительные предложения обладают существенно большей просодической вариативностью по сравнению с идентичными им по сегментному составу восклицаниями. Автором работы был обнаружен значимый эффект индивидуальных характеристик говорящего (не связанный с полом информантов), а также зависимость контура частного вопроса от характеристики входящих в него слов по параметру данное/новое.

Наконец, в качестве примера из романских языков можно привести работу [Sosa 2003], в которой был проведен сравнительный анализ распределения вариантов тонального оформления частных вопросов в четырех латиноамериканских диалектах испанского языка. В работе также отмечается роль информационной структуры предложения, кроме того, делается вывод о том, что важнейшим прагматическим фактором, влияющим на выбор контура, является то, какого ответа говорящий ожидает от собеседника: содержащего новую информацию либо же подтверждающего уже имеющуюся в контексте.

Аналогичные экспериментальные исследования на материале русского языка ранее не проводились. Несмотря на то что вариативность интонации русских частных вопросов зафиксирована в большинстве существующих описаний, данные о статусе и функциях мелодических контуров, используемых в этом типе высказываний, противоречивы. Так, в модели Е. А. Брызгуновой начиная с ранних ее версий контур с падением тона на вопросительном слове характеризовался как основной способ оформления частного вопроса, однако при этом отмечалась возможность «передвижения логического ударения» и его дублирования для выражения «смысловых оттенков» [Брызгунова 1963: 255-258]. Впоследствии в модели укрепилась идея о том, что вариант оформления частного вопроса с падением тона на вопросительном слове является немаркированным, а передвижение центра интонационной конструкции выступает в качестве средства выражения «смыслового выделения или противопоставления» [Брызгунова 1980a: 111].

\footnotetext{
${ }^{2}$ В настоящей работе термин т о нальны й а кц е н т употребляется для передачи англоязычного термина pitch accent, используемого в автосегментной метрической модели интонации. В русскоязычной литературе в сходной функции используются термины интонационный центр, фразовое ударение, а к ц е н т. См. обсуждение этих терминов в [Николаева 1982: 7-12; Оде 2007; Янко 2008: 29].
} 
В работах Е. А. Брызгуновой также зафиксированы иные способы интонационного оформления русского частного вопроса. В частности, отмечается, что при выражении вопроса, «который связан сопоставительными отношениями с предыдущим предложением», а также «в вопросах, следующих друг за другом», может использоваться нисходяще-восходящий контур, получивший в модели Е. А. Брызгуновой название «четвертой интонационной конструкции», или ИК-4. Отдельно утверждается, что ИК-4 в частных вопросах «усиливает $\langle\ldots\rangle$ оттенки недовольства и назидания» [Там же: 114], выражает «назидание или недовольство при вопросе», «оттенок неудовольствия» [Брызгунова 1980б: 234]. В рамках настоящей работы важно отметить, что в качестве примеров «назидательного» вопроса приводятся только фразы с центром ИК-4 на вопросительном слове (Почему ${ }^{4}$ ты пришла так поздно?; цифрой в примере обозначен гласный просодически выделенного слога - центра ИК). Имеют ли аналогичную характеристику частные вопросы с центром ИК-4 на других словах фразы, не обсуждается, однако указание на наличие этой функции только у вопросов с центром на местоимении обнаруживается в [Там же: 401].

Наконец, согласно данным Е. А. Брызгуновой, еще одним маркированным средством интонационного оформления частного вопроса является ИК-5 (контур, содержащий два тональных акцента, восходящий и нисходящий, соединенные ровным высоким тоном). Для этой мелодии в частном вопросе предлагается функция «выражения нетерпения, досады»: Когда ${ }^{5}$ же он прие дет? [Брызгунова 1980a: 116].

Утверждения о немаркированном характере контура с падением тона (ИК-2) на вопросительном местоимении и деакцентуацией следующих за ним слов частного вопроса оспаривались в независимых от системы Е. А. Брызгуновой описаниях русской интонации. Так, Н. Д. Светозарова, отмечая дискуссионность вопроса, указывает, что такая конфигурация является более редкой по сравнению с контуром ИК-5 [Svetozarova 1998: 272]. Неоднократно обращался к проблеме вариативности интонации частного вопроса С. В. Кодзасов. Если в работе [Кодзасов 1985] контур с падением тона на вопросительном слове характеризуется как немаркированный («вопросительное местоимение, как правило, несет нейтральный нисходящий акцент», цит. по [Кодзасов 2009: 180]), то начиная с текстов 1990-х гг. «обычным» контуром специального вопроса последовательно называется «шляпная» конструкция ИК-5 [Кодзасов 1996: 96].

С. В. Кодзасов выделяет ряд факторов, которые, по его наблюдениям, обуславливают выбор носителями языка тех или иных вариантов просодического оформления частного вопроса. Так, в [Кодзасов 1996] падение тона на вопросительном слове связывается с актуальным членением предложения: деакцентуация слов, следующих за вопросительным местоимением, возможна, если они «актуализованы» в левом контексте. Там же выделяются фонетические средства маркирования «экзаменационного вопроса»: усиление интенсивности и интервала падения тона на вопросительном 
слове. В [Кодзасов 2009] подробнее рассматривается тема-рематическая структура русского частного вопроса: согласно представленному в работе анализу, «ремой специальных вопросов является вопросительное местоимение, находящееся обычно в начале предложения, а новая тема помещается в конце» [Там же: 108-109]. Таким образом, утверждается, что частный вопрос в нормальном случае содержит два тональных акцента: один маркирует рему, а другой - тему. Если второй акцент всегда нисходящий, то выбор акцента на вопросительном слове может быть обусловлен позицией говорящего: занимая доминирующее положение, он может использовать нисходящее движение тона на вопросительном слове вместо восходящего, в результате чего «шляпная» конструкция трансформируется в контур с двумя падениями тона. Что касается контура ИК-4, то, как и Е. А. Брызгунова, С. В. Кодзасов допускает его использование в частном вопросе только в цепочке реплик; согласно его анализу, высокий пограничный тон имеет функцию «показателя текстовой связности (ожидания продолжения текста)» [Там же: 108].

Близкий к перечисленным выше работам анализ вариативности просодии частных вопросов представлен в [Янко 2008: 177], где выбор вопросительного слова в качестве акцентоносителя связывается со значениями сетования или упрека, в то время как в нейтральном частном вопросе носителем фразового акцента выступает одно из слов, следующих за местоимением.

Таким образом, существующие описания русской интонации демонстрируют, с одной стороны, отказ от утверждения о немаркированном характере контура с единственным нисходящим фразовым акцентом, реализующимся на вопросительном слове, и, с другой стороны, попытки предложить функциональную интерпретацию вариативности контуров частновопросительных предложений. Безусловно, в отсутствие эмпирических данных такие интерпретации должны приниматься с осторожностью.

Экспериментальные исследования русской интонации последних двух десятилетий уделяли частным вопросам значительно меньше внимания по сравнению с различными типами невопросительных предложений и общими вопросами [Makarova 2001; 2007; Rathcke 2006; 2013; 2017; Meyer, Mleinek 2006]. Данные о вариативности просодии частных вопросов отсутствуют также в анализе русской интонации, представленном в работах С. Оде. Если в первом варианте модели, предложенном в [Odé 1989], не ставилась цель функциональной интерпретации контуров, выделенных на основании принципа перцептивной эквивалентности, то в более позднем модифицированном варианте, воплощенном в системе транскрипции ToRI [Odé 2008], представлен в целом традиционный для русской интонологии анализ частновопросительных предложений: утверждается, что в частном вопросе «с узким фокусом» используется нисходящий тональный акцент $\mathrm{HL}^{*}$, при этом указывается, что вопрос с падением на вопросительном слове «звучит для русского уха как несколько нетерпеливый и даже невежливый» [ToRI-2008]. 
Примерами экспериментально-фонетического анализа просодии русских частных вопросов являются работы Й. Игараси [Igarashi 2006; 2008]. Основное ограничение этих исследований в том, что их автор сознательно не учитывает вариативность контуров частного вопроса в русском языке, указывая, что в произношении его информантов встретились только контуры с падением тона на вопросительном слове. Сравнивая контуры частного и общего вопросов на материале почти идентичных по сегментному составу фраз (например, Какой номер? и Такой номер?), Й. Игараси приходит к выводу о том, что фонетическая реализация тонального акцента, ассоциированного с вопросительным словом частного вопроса, отличается от реализации тонального акцента в общем вопросе более ранним таймингом и меньшей частотой пика ЧОТ, а также отсутствием «локтя», «перелома» контура в восходящем движении тона [Igarashi 2006: 190]. На основании фонетических данных исследователь предлагает интерпретировать в рамках автосегментной метрической модели (далее - АМ-модель, подробнее о ней см. ниже, в разделе 3) контур русского частного вопроса (аналог ИК-2 Е. А. Брызгуновой) как тональную конфигурацию H*+L L L\% либо H* L L\% [Ibid.: 194].

Анализ существующих описаний интонации русского частного вопроса указывает на необходимость дальнейшего экспериментального исследования вариативности в этом типе фраз. Именно эту цель ставило перед собой настоящее исследование. Во-первых, в его рамках предполагалось в экспериментальных условиях проверить имеющиеся в литературе утверждения о фонетической реализации вариантов просодического оформления русских частных вопросов. Во-вторых, на основании фонетических данных планировалось предложить предварительную фонологическую интерпретацию зафиксированных вариантов в рамках АМ-модели. Наконец, втретьих, ставилась цель начать изучение факторов, способных влиять на выбор контура частного вопроса носителями русского языка. В рамках настоящего исследования были выбраны два таких фактора: тип фокуса (информационный/контрастный) и наличие/отсутствие во фразе инициальной частицы $a$. О причинах этого выбора пойдет речь в следующем разделе.

\section{2. Описание эксперимента}

\section{1 Материаль эксперимента}

В качестве стимулов в эксперименте были использованы частновопросительные предложения с тремя вопросительными словами: где, когда и nочему. Эти местоимения были выбраны по двум причинам. Во-первых, ставилась цель сбалансировать количество слогов в местоимениях $(1,2$ и 3 соответственно) и проконтролировать положение ударения (все слова имеют ударение на последнем слоге). Во-вторых, ударные слоги выбранных слов не содержат глухих согласных, что способствует корректному 
анализу движений ЧОТ на просодически выделенных сегментах. Для каждого местоименного слова была составлена фраза-стимул, состоящая из трех или четырех фонетических слов, расположенных в нейтральном для русского языка порядке: Где она работает? Когда он приехал? Почему вы ему не позвонили?

Для элицитации натуральных произнесений исследуемых стимулов они были встроены в естественные диалогические контексты. Таким образом, для каждого из трех частных вопросов был составлен диалог, представляющий собой беседу двух персонажей на бытовую тему. Каждый диалог содержал четыре или пять реплик и имел следующую структуру:

1) вводная реплика информанта, не требующая контекста (одна или две фразы; последняя фраза обязательно содержит вопрос);

2) ответ экспериментатора (одно или два повествовательных предложения);

3) реакция информанта на ответ экспериментатора (повествовательное предложение + частный вопрос-стимул);

4) второй ответ экспериментатора;

5) факультативная заключительная реплика информанта.

См. ниже пример диалога, использовавшегося в эксперименте.

(1) (Информант): А где твой брат? Разве он не пойдет с нами в кино? (Экспериментатор): Я не знаю. Наверное, как обычно, дома за компьютером сидит.

(И): Без него будет скучно. Почему вы ему не позвонили?

(Э): Если хочешь, звони сам(а). Могу тебе номер продиктовать.

(И): Давай, записываю!

Поскольку одна из целей исследования - изучение факторов, обуславливающих вариативность просодии частного вопроса, составленные стимулы были подвергнуты манипулированию по двум признакам, описанным ниже в разделах 2.1.1 и 2.1.2.

\subsection{1. Информационная структура:}

ин формационный и контрастный фокус

Как было показано во введении, авторы исследований, посвященных вариативности интонации частного вопроса в языках мира, сходятся в том, что один из основных факторов, влияющих на выбор конфигурации тональных акцентов в этом типе фраз, - информационная структура высказывания. Под этим термином в настоящей работе мы понимаем вслед за [Krifka 2008; Zimmermann, Féry 2010] способ представления говорящим информации в высказывании в целях коммуникации, основными составляющими которого являются противопоставления по признакам фокус/ фон (англ. focus/background), тема/рема (англ. topic/comment) и данное/ новое (англ. given/new). Эти когнитивные категории могут оказывать 
влияние на просодию фразы как по отдельности, так и во взаимодействии друг с другом, причем фонетические средства маркирования элементов информационной структуры лингвоспецифические [Breen et al. 2010; Calhoun 2010; Baumann 2012; Féry, Ishihara 2016]. В рамках настоящего исследования при составлении стимулов мы проводили манипуляции только с одной из трех составляющих информационной структуры - типом фокуса. Под фокусом в данном случае понимается «наличие альтернатив, релевантных для интерпретации языковых выражений» ([Krifka 2008: 247]; перевод определения на русский язык взят из работы [Шкапа 2013]). В нашем исследовании в качестве экспериментальных условий использовались две разновидности фокуса [Kiss 1998]: информационный (не содержащий информации о релевантности альтернатив) и контрастный в одной из его основных функций - корректирующей, указывающей на релевантность для говорящего только одной из имеющихся альтернатив (о понятии «корректирующий фокус» см. также [Gussenhoven 2008: 11-12]).

Так, в приведенном выше примере (1) реализуется информационный фокус (далее - ИФ). Говорящий использует вопросительное слово, а затем описывает ситуацию (вы ему не позвонили), при этом в высказывании отсутствует указание на существование альтернативных ситуаций или их релевантность для коммуникации. Сравним приведенный ниже пример (2), в котором тот же частный вопрос содержит корректирующий фокус на предикате (далее - КФП), а также пример (3), в котором частный вопрос содержит корректирующий фокус на субъекте (далее - КФС). Здесь и далее слово - носитель контрастного фокуса заключается в квадратные скобки.

(2) (И): Вы Сереже сказали, что мы в парк идем?

(Э): Мы ему записку на столе оставили. И еще сообщение на «Фейсбуке» написали.

(И): Да он же эти сообщения никогда не читает! Почему вы ему не [позвонили]?

(Э): Он что, читать не умеет? Ладно, давай сейчас позвоним.

(И): Звоните скорее, а то он обидится.

(3) (И): У Саши сегодня день рождения. Вын не забыли ему позвонить?

(Э): Кажется, ему звонила моя сестра. И Вова его точно поздравлял.

(И): Я не сомневалась (сомневался), что Вова позвонил. Почему [вы] ему не позвонили?

(Э): У нас не было времени!

(И): Ну тогда звоните сейчас. Лучше поздно, чем никогда.

Основываясь на данных существующих описаний русской интонации, мы предполагаем, что в обоих примерах для того, чтобы частный вопрос был осмысленным в заданном контексте, говорящий должен использовать просодические средства для маркирования контрастного корректирующего фокуса - информации о том, что другие имеющиеся в контексте альтер- 
нативы («написать, а не позвонить» в (2), «сестра и Вова, а не мы» в (3)) не интересуют говорящего и, следовательно, должны быть исключены из дальнейшего процесса коммуникации.

Вопросы в примерах (1), (2) и (3) одинаковы с точки зрения сегментного состава, что позволяет корректно сравнивать их просодическую реализацию. Анализ вопросов третьего типа, однако, показал, что фразы с контрастным фокусом на субъекте, выраженном личным местоимением (Когда [он] приехал? Где [она] работает?), требуют очень широкого контекста. Чтобы избежать ошибок, связанных с непониманием информантами комплексных контекстов, во фразах с вопросительными словами когда и где в условии КФС местоимения были заменены сходными по ритмической структуре и сегментному составу существительными: сын вместо он и жена вместо она. Вопросы с почему были оставлены без изменений.

\subsection{2. Инициальная частица $a$}

Кроме того, в рамках работы была выдвинута гипотеза о том, что на выбор интонации частного вопроса носителями русского языка при чтении заранее составленных фраз может оказывать влияние наличие/отсутствие частицы $a$ в начале вопросительного предложения. Прежде чем перейти к обоснованию этого предположения, следует отметить, что частица $а$ функционирует неодинаково в разных типах вопроса в русском языке. Если в неполных сопоставительных вопросах (Алена пришла? - Да, Алена пришла. - A Наташа?) ее употребление, сопровождаемое конфигурациями тональных акцентов ИК-4 или ИК-6 ${ }^{3}$, является обязательным, то в прочих типах вопросительных предложений употребление $а$ факультативно. Тем не менее частица является достаточно частотной как в частных, так и в общих вопросах. Нам неизвестны корпусные исследования на эту тему, однако, например, в статье «Русской грамматики» 1980 г., посвященной вопросительным предложениям [РГ-1980: 386-401], насчитывается около ста примеров вопросов с инициальным $a$, из них более половины - вопросы с вопросительными словами. При этом в тексте статьи указываются только две функции такого употребления частицы: оформление эллиптического вопроса со значением «напоминания о существенном, с чем-л. связанном и чему-л. противопоставляемом» [Там же: 390] и вопроса, «в котором неизвестное сопоставляется с предшествующим, уже известным» [Там же: 397]. В качестве еще одного примера, подтверждающего тезис о частотности вопросов с $a$, можно привести «надкорпусную базу данных», использовавшуюся в исследовании [Зализняк, Микаэлян 2018а], где 55,3 \% всех употреблений $a$ в абсолютном начале фразы пришлись на вопросительные предложения.

\footnotetext{
${ }^{3}$ Мы благодарим одного из анонимных рецензентов за указание на высокую частотность использования ИК-6 в неполном сопоставительном вопросе, зафиксированную в корпусных данных.
} 
Подробное описание семантики и прагматики русского $a$, объединяющее результаты многочисленных предыдущих исследований этого слова, представлено в работе [Зализняк, Микаэлян 2018б]. В статье отдельно рассматриваются внутренний союз $a$ и $a$ инициальное, которое может функционировать как союз, частица или междометие. Авторы исследования приходят к выводу о том, что по своим функциям эти две языковые единицы различаются несущественно. Таким образом, инициальное $a$, как и внутренний союз, «маркирует подключение высказывания к... предтексту» и выражает различные «логико-семантические отношения между репликами диалога»: отношения сопоставления (нейтрального и контрастного), несоответствия и аддитивное [Там же: 337]. Вслед за [Николаева 1997], помимо лингвистических функций $a$, в работе выделяется характерная для этой единицы экстралингвистическая функция «интимизации» в бытовом диалоге.

В рамках настоящего исследования важно также обратить внимание на анализ связи внутреннего $а$ с интонацией, представленный в [Фужерон 1997]. Анализируя тональные контуры предложений, различающихся только союзами (Вылила Матильда, а/и за ней Мохов и т. п.), автор исследования показывает, что различия в тема-рематической структуре, передаваемые в этих фразах выбором союза, маркируются и различиями интонационными. Эта идея развивается в [Подлесская 2018], где на материале звучащего корпуса рассматривается просодия фразы или части сложного предложения, предшествующей $a$ (как внутреннему, так и инициальному).

Тем не менее вопрос о характере связи между интонацией частного вопроса и наличием в нем инициального $а$ остается открытым. Существующие описания русской интонации содержат многочисленные примеры частных вопросов с частицей $a$, однако особенности их просодической реализации отдельно не обсуждаются. Релевантные данные на этот счет обнаруживаются только в ранних работах Е. А. Брызгуновой, созданных еще до выделения первых интонационных конструкций, где автор эксплицитно указывает, что «неполное вопросительное предложение с вопросительным словом и союзом $а$ может иметь два варианта интонации: или такую, как в полном предложении, или такую, как в неполном вопросительном с союзом а» [Брызгунова 1963: 257]. Для проверки этих данных в рамках эксперимента было произведено манипулирование дополнительным параметром. Для каждого из частных вопросов, описанных в разделе 2.1.1, в эксперимент была включена пара, содержащая инициальную частицу $a$. Так, например, кроме диалога, приведенного в примере (1), в материал эксперимента был включен такой же диалог, но содержащий вопрос с $a$ ( А почему вы ему не позвонили?), и т. д. для всех стимулов.

\section{2 Методы эксперимента}

В общей сложности материал эксперимента составили диалоги, содержащие 18 частновопросительных предложений: с тремя вопросительными словами (почему, когда, где) в трех контекстах (ИФ, КФП, КФС) при от- 
сутствии и наличии инициальной частицы $a$. Также в материал эксперимента были включены 32 филлера - диалоги, схожие по структуре и содержанию с экспериментальными стимулами. Каждому участнику предложены все 50 диалогов в одной из четырех последовательностей. Последовательности были составлены таким образом, что похожие стимулы находились на расстоянии нескольких диалогов друг от друга ${ }^{4}$.

В ходе эксперимента информантам предлагалось прочитать «по ролям» вместе с экспериментатором диалоги, представленные на слайдах на экране компьютера. Участники эксперимента могли ознакомиться с каждым текстом перед его прочтением. Важно отметить: перед началом экспериментальной сессии участникам сообщалось, что многие диалоги будут повторяться дважды, однако на самом деле полностью повторялись только филлеры, в то время как все экспериментальные стимулы различались как минимум наличием $a$. За счет этого удалось достичь того, что участники эксперимента не догадались о манипуляциях, произведенных с частицей.

\section{3 Участники эксперимента}

В эксперименте приняли участие 20 носителей русского языка (14 женщин, 6 мужчин, средний возраст - 26,5 лет, $\sigma=5.7)$. Все информанты являются носителями литературного произношения и на момент записи постоянно проживали в Москве, работая или получая высшее образование. Исключение составил один участник эксперимента, незадолго до записи переехавший из Москвы. Длительность каждой экспериментальной сессии составляла 15-20 минут.

\section{3. Результаты эксперимента}

По итогам эксперимента получены 360 записей произнесения частных вопросов. Из них 15 (4,17 \%) исключены из дальнейшего анализа по двум основным причинам: 9 фраз содержали различные оговорки информантов, связанные с пропуском слов или изменением порядка слов; также из анализа исключены 6 примеров, в которых частный вопрос был произнесен с интонацией переспроса ${ }^{5}$.

\footnotetext{
${ }^{4}$ Полный список диалогов размещен в онлайн-приложении к статье, см. https://osf.io/dgv3s.

${ }^{5}$ В речи пяти участников эксперимента встретился вариант «ложного переспроса», когда говорящий использовал характерную интонацию переспроса (например, Когда ${ }^{6}$ сын приехал? с повышением тона на вопросительном слове и сохранением высокого ровного тона на всем протяжении фразы; ИК-6 в системе Е. А. Брызгуновой), несмотря на то что запрашиваемая информация отсутствовала в контексте. Поскольку в рамках настоящего исследования мы рассматривали только собственно вопросительные предложения, эти примеры были исключены из анализа.
} 
Остальные 345 записей фраз проанализированы в программе Praat [Boersma, Weenink 2019]. В ходе инструментального анализа произведена ручная сегментация экспериментальных стимулов на слоги и слова, а также полуавтоматическая разметка основных релевантных тональных событий, т. е. локальных максимумов и минимумов ЧОТ, ассоциированных с ударными слогами просодически выделенных слов ${ }^{6}$. Такая разметка позволяет охарактеризовать фонетическую реализацию тональных акцентов по трем основным признакам: абсолютной и относительной высоте тона, а также таймингу - положению тонального события относительно границ сегментов.

На основании данных фонетического анализа были выделены основные типы контуров, использовавшихся информантами. Для каждого типа тональной конфигурации, обнаруженного в речи информантов, ниже предложена фонологическая интерпретация в терминах АМ-модели. Ограничения по объему не позволяют нам подробно остановиться на теоретических положениях этой широко используемой в современной интонологии концепции. Подробные обоснования основных допущений теории представлены, например, в работах [Pierrehumbert 1980; Gussenhoven 2004; Ladd 2008]. Укажем кратко, что с точки зрения АМ-модели интонационный контур на фонологическом уровне состоит из последовательностей высоких и низких тонов (условно обозначаемых в транскрипции как H и L), которые фонетически реализуются как тональные цели, т. е. особые точки в контуре ЧОТ, обычно - локальные минимумы и максимумы [Arvaniti, Ladd 2009: 47-48]. Важным отличием автосегментной модели интонации от других современных моделей является представление о «разреженной» тональной спецификации (англ. sparse tonal specification). В АМ-модели отрицается необходимость тональной спецификации каждого слога; утверждается, что тональный контур может быть смоделирован за счет проекции тональных целей на просодически выделенные сегменты (чаще всего ударные слоги просодически выделенных слов или их окружение) и интерполяции движений ЧОТ от одной «цели» к другой (не обязательно в виде прямых линий). Одним из результатов развития АМ-модели стало создание специфических систем фонологической транскрипции интонации (ТoBI-транскрипций, от англ. Tones and Break Indices) сначала для английского [Beckman, Pierrehumbert 1986], а затем и для ряда других языков [Jun 2005; 2014].

Первые шаги в направлении создания автосегментного анализа русской интонации и его формулировки в символах ТоBI-транскрипции были сделаны в исследованиях С. Оде [Odé 2005; 2008; ToRI-2008], Й. Игараси

\footnotetext{
${ }^{6}$ Сегментация на слоги производилась автором работы вручную на основании данных осциллограмм и спектрограмм; определение положения локальных минимумов и максимумов ЧОТ выполнялось автоматически с использованием алгоритмов программы Praat.
} 
[Игараси 2002; Igarashi 2006; 2008], Т. Ратке [Rathcke 2006; 2013; 2017], О. Йокоямы [Йокояма 2003]. В рамках настоящей работы мы планируем продолжить линию этих исследований, предложив автосегментную интерпретацию вариантов просодического оформления русских частных вопросов и ТоВI-транскрипцию для контуров, встретившихся в данных нашего эксперимента. Следует, однако, особо отметить, что предложенные в статье фонологические интерпретации и варианты транскрипции должны рассматриваться как предварительные. Как показывает опыт исследования языков с детально изученной просодией, создание непротиворечивого лингвистического описания отдельно взятой просодической системы требует критической экспериментальной проверки любых теоретических обобщений.

\section{1. Тональные конфигурации в вопросах с ИФ}

В результате анализа данных были выделены четыре основных тональных контура, использовавшихся участниками эксперимента в частных вопросах. Ниже, в разделах 3.1.1-3.1.4, они подробно рассмотрены на примере стимулов с информационным фокусом. Распределение контуров в контекстах с контрастным фокусом на предикате и субъекте рассматривается в разделах 3.2 и 3.3 соответственно. Полные данные классификации контуров представлены в Таблице 1 (все таблицы см. в Приложении).

\subsection{1. Падение тона на вопросительном слове ${ }^{7}+$ де ак це н т у а и я}

Вариант с нисходящим движением тона на вопросительном слове и отсутствием тональных акцентов (деакцентуацией) на последующей части фразы, в системе Е. А. Брызгуновой характеризуемый как основной немаркированный способ просодического оформления русского частного вопроса (ИК-2), оказался частотным и в наших данных, в первую очередь в контекстах информационного фокуса. Этот вариант контура ЧОТ начинается на среднем, нейтральном для говорящего, уровне (или, реже, высоком, особенно при отсутствии предударных слогов в начале фразы) и достигает максимума в начале или середине ударного слога вопросительного слова $\left(\right.$ см. рис. $1^{8}$ ). Нисходящее движение тона может характеризоваться разной степенью крутизны в зависимости от сегментного состава фразы: оно начинается на ударном слоге вопросительного слова и чаще всего продолжается на примыкающем к нему деакцентуированном слове (в наших стиму-

\footnotetext{
${ }^{7}$ Всюду в работе, говоря о повышении или падении тона на том или ином слове, мы подразумеваем повышение или падение тона, ассоциированное с просодически выделенным слогом этого слова, а не движение тона на всех его слогах. Не вполне точное выражение «повышение/падение тона... на слове» используется нами исключительно для краткости и упрощения восприятия текста.

${ }^{8}$ Аудиозаписи произнесений фраз, представленных на иллюстрациях, доступны в онлайн-приложении.
} 
лах — личном местоимении или существительном в роли субъекта). Нижняя граница ЧОТ достигается в районе ударного слога последнего слова фразы (в наших стимулах - предиката) и сохраняется до конца фразы.

Судя по имеющимся в литературе описаниям этого контура, такая тональная конфигурация воспринимается носителями языка как содержащая только одно фразовое ударение - на вопросительном слове. Таким образом, в рамках АМ-модели она должна быть проанализирована как содержащая один тональный акцент. Вслед за [Igarashi 2008] мы анализируем этот тональный акцент как $\mathrm{H}^{*+\mathrm{L}}$. Эта автосегментная нотация подразумевает, что тональный акцент содержит два тона (высокий и низкий), при этом высокий тон, отмеченный астериском, ассоциирован с ударным слогом (поскольку его «тональная цель» расположена рядом с центром выделенного слога), а низкий тон реализуется после него на доступном сегментном материале.

Необходимо также предложить фонологическую интерпретацию тонального движения на участке фразы, следующем за последним тональным акцентом. В классическом варианте АМ-модели [Beckman et al. 2005] выделяются два типа пограничных тонов (англ. edge tones): тоны, ассоциированные с границей фразы и реализующиеся на ее последнем слоге (англ. boundary tones; в ТоВІ-транскрипции они обозначаются символом $T \%$, где $T$ - любой тон), и тоны, реализующиеся на всей последовательности слогов от последнего тонального акцента до последнего слога фразы (англ. phrase accents, для их транскрипции используется символ $T$-). Необходимость введения в АМ-модель двух уровней пограничного тона была продемонстрирована для описания комплексных контуров, представленных, например, в английском [Pierrehumbert 1980], греческом [Arvaniti, Ladd 2009] и ряде других языков [Grice et al. 2000]. В настоящий момент не существует надежных экспериментальных данных, доказывающих существование в русском литературном произношении значимых движений тона, ассоциированных с последним слогом фразы. Судя по имеющимся описаниям просодии русского языка, носителем пограничного тона всегда выступает последовательность слогов, примыкающая справа к слогу - носителю последнего тонального акцента во фразе. В связи с этим, например, в транскрипции русской интонации, предложенной в [Odé 2008], тональная характеристика просодически невыделенных слогов конца фразы обозначается отдельным символом L\% только в том случае, если фраза заканчивается на низком уровне ЧОТ, при этом нередкий в русском языке «высокий конечный уровень» транскрибируется иным способом - как реализация второй «тональной цели» акцента $\mathrm{H}^{*} \mathrm{H}$ или $\mathrm{L} * \mathrm{H}$ [Ibid.], распространяющаяся на всю последовательность заударных слогов; конец фразы при этом обозначается одиночным символом \%.

Нам представляется более последовательным подход Т. Ратке, которая, опираясь на анализ просодии немецкого языка, где, как и в русском, отсутствуют тональные движения, ассоциированные с последним слогом фразы, 
предлагает отказ от использования специальных символов для различения двух уровней пограничных акцентов и использует нотацию $T \%$ для описания русских пограничных тонов [Rathcke 2017]. По нашему мнению, такая нотация может приниматься за ассоциацию тонального движения с последним слогом фразы. В связи с этим в настоящей работе мы используем другой вариант нотации, также обсуждавшийся в [Ibid.] и используемый в транскрипции немецкого языка GToBI [Grice et al. 2005], - T-\%. Следовательно, для анализа типа контура, описанного в разделе 3.1.1, мы предлагаем автосегментную интерпретацию, которая в ТоВІ-транскрипции может быть записана как $\mathrm{H}^{*}+\mathrm{L} \mathrm{L-} \%$; см. разметку на рис. 1.

\subsection{2. Падение тона на вопросительном слове + падение тона на последнем слове фразы}

Реализация нисходящего тонального акцента $\mathrm{H}^{*}+\mathrm{L}$ на вопросительном слове в речи участников эксперимента не всегда сопровождалась полной деакцентуацией последующей части фразы. Напротив, во фразе с наибольшим количеством слогов (A) почему вы ему не позвонили? деакцентуация встречалась редко. Наиболее частотным в этой фразе оказался контур с дополнительным просодическим выделением последнего слова фразы, которое фонетически реализуется повторным падением тона на ударном слоге (рис. 2). Начало этого контура не отличается от описанного в предыдущем разделе и представляет собой падение тона на ударном слоге вопросительного слова. Далее в районе ударного слога глагола наблюдается небольшой подъем ЧОТ («занос», неоднократно описанный в русской интонологии, в частности в [Keijsper 1983; Odé 1989; Кодзасов 2009]) и второе падение, локальный максимум которого обычно имеет ранний тайминг и располагается на предударном слоге.

Важно отметить, что второй пик регулярно характеризуется меньшим значением ЧОТ по сравнению с первым. Понижение ЧОТ на протяжении фразы в АМ-модели описывается двумя терминами: деклинация и даунстеп. Деклинация - это автоматическое, не зависящее от контекста понижение тона, вызванное физиологическими причинами и, по всей видимости, имеющее универсальный характер. Даунстеп же представляет собой «фонологизацию» деклинации, фонологическое правило, согласно которому в определенных контекстах (например, после некоторых тональных конфигураций) тональные акценты, содержащие высокий тон, на фонетическом уровне реализуются пиками с пониженными абсолютными значениями ЧОТ [Ladd 1984]. Имеющиеся в литературе экспериментальные данные, безусловно, подтверждают наличие деклинации в русском языке [Odé 1989; Svetozarova, Kuosmanen 2003]. В частности, интерес в этом отношении представляют исследования [Kocharov et al. 2014; 2015], демонстрирующие, что наличие/отсутствие градуального понижения тона в русской фразе контролируется говорящим и может маркировать различия между типами предложений. Тем не менее вопрос о фонологическом статусе 
наблюдаемых явлений в существующих работах на материале русского языка эксплицитно не рассматривается. Данные нашего эксперимента также не позволяют однозначно решить эту проблему. Чтобы отразить указанную неопределенность, в нашем анализе мы используем традиционный для ТоBI-транскрипций знак даунстепа «!», однако заключаем его в круглые скобки. «Раскрыть» эти скобки позволят будущие экспериментальные исследования, посвященные фонологической интерпретации систематического понижения ЧОТ во фразе в русском языке.

Итак, поскольку контуры обоих тональных акцентов имеют схожий тайминг («непоздний»; см. о позднем тайминге в следующем разделе) и различаются только частотой пика (и, следовательно, диапазоном падения тона), мы анализируем эту тональную конфигурацию как содержащую два одинаковых тональных акцента $\mathrm{H}^{*}+\mathrm{L}$. Второй контур на фонетическом уровне имеет более низкий уровень ЧОТ, вероятно, в связи с применением фонологического правила, которое активируется низким тоном первого тонального акцента фразы. Возможность такой интерпретации мы обозначаем символом даунстепа, заключенным в круглые скобки. Таким образом, описанный контур может быть предварительно затранскрибирован как $\mathrm{H}^{*}+\mathrm{L}(!) \mathrm{H}^{*}+\mathrm{L} \mathrm{L}-\%$.

\subsection{3. Повышение тона на вопросительном слове и падение тона на последнем слове фразы}

Третьей конфигурацией, встретившейся в экспериментальных данных, является так называемый «шляпный» контур (ИК-5 в системе Е. А. Брызгуновой). Эта последовательность тональных акцентов реализуется контуром ЧОТ, начинающимся на нейтральном для говорящего уровне и достигающим максимума в середине или конце ударного слога вопросительного слова. Далее высокий ровный тон поддерживается на протяжении фразы вплоть до последнего слова (незначительное понижение тона на этом участке, вероятно, должно интерпретироваться как автоматическая деклинация). В районе ударного слога второго просодически выделенного слова наблюдается нисходящее движение тона с факультативным «заносом» и ранним таймингом (рис. 3).

Мы предлагаем анализировать этот вариант как содержащий два тональных акцента (и, разумеется, пограничный тон). Второй тональный акцент, ассоциированный с последним словом фразы, может быть отождествлен с рассмотренным в двух предыдущих разделах $\mathrm{H}^{*}+\mathrm{L}$. Напротив, первый тональный акцент «шляпного» контура, ассоциированный с вопросительным словом, требует отдельного обсуждения. Следует обратить внимание на то, что его фонетическая реализация существенно отличается от той, что была зафиксирована для первого тонального акцента в предыдущем разделе. Два основных отличия - это поздний тайминг пика и отсутствие значимого понижения тона после локального максимума ЧОТ. Как известно, восходящий тональный акцент с поздним таймингом представлен, на- 
пример, в русском общем вопросе, где при наличии заударных сегментов за ним обязательно следует низкий пограничный тон. В разных автосегментных описаниях тональный акцент, маркирующий русский общий вопрос и описанный как ИК-3 в модели Е. А. Брызгуновой, анализировался как L+H* [Igarashi 2006; 2008] или L*+H [Rathcke 2017]. Общей для всех описаний является необходимость постулирования именно битонального акцента, связанная с обнаружением в контуре частного вопроса перцептивно важной «переломной точки», «локтя» [Igarashi 2006], который увеличивает крутизну восходящего тонального движения [Rathcke 2006]. Boпрос о том, может ли первый тональный акцент «шляпного» контура приравниваться к тональному акценту общего вопроса, остается открытым и требует дополнительной экспериментальной проверки, в частности определения наличия «локтя» в подъеме ЧОТ. Во избежание преждевременного отождествления этих единиц в рамках настоящего исследования мы предварительно анализируем восходящий акцент как монотональный $\mathrm{H}^{*}$ и весь контур, следовательно, как $\mathrm{H}^{*} \mathrm{H}^{*}+\mathrm{L} \mathrm{L}-\%$.

\subsection{4. Повышение тона на вопросительном слове и нисходяще-восходящая конфигурация на остальной части фразы}

Наконец, частотным в контекстах информационного фокуса оказался контур, имеющий в модели Е. А. Брызгуновой название ИК-4. В этом варианте ЧОТ начинается на среднем, нейтральном для говорящего, уровне и достигает максимума в конце ударного слога вопросительного слова. Далее тон неравномерно понижается, достигая минимума на ударном слоге последнего слова фразы. После этого происходит повышение тона, тайминг которого, по нашим наблюдениям, зависит не только от количества заударных сегментов, но и от индивидуальных предпочтений диктора. Обычно подъем ЧОТ начинается либо на второй половине ударного слога, либо на первом заударном слоге; после достижения максимума на одном из заударных слогов поддерживается высокий ровный тон (рис. 4).

Насколько нам известно, контур ИК-4 ранее не подвергался анализу в рамках АМ-модели. Основываясь на наших данных, а также на данных традиционных описаний русской интонации, мы предлагаем предварительно анализировать этот контур как последовательность из двух тональных акцентов и высокого пограничного тона Н-\%. Первый тональный акцент, ассоциированный с вопросительным словом и имеющий поздний тайминг, мы анализируем как $\mathrm{H}^{*}$, предварительно отождествляя его (на основании акустического признака «поздний тайминг») с первым тональным акцентом «шляпного» контура. Что касается второго тонального акцента, то, по нашему мнению, возможны два основных варианта его интерпретации: монотональный L* и битональный L*+H. Нам представляется предпочтительным первый вариант по двум основным причинам. Во-первых, как и в случае со «шляпным» контуром, мы бы хотели избе- 
жать отождествления этого тонального акцента с акцентом, маркирующим общий вопрос, в частности в анализе [Rathcke 2017]. Во-вторых, этот вариант представляется более «экономным», поскольку он не усложняет фонологическую репрезентацию, допуская, что подъем от низкого тона тонального акцента к высокому тону акцента пограничного является результатом интерполяции. Таким образом, предварительный автосегментный анализ контура, зафиксированного в наших данных и соответствующего ИК-4 системы Е. А. Брызгуновой, может быть отражен в ТоВІ-транскрипции как $\mathrm{H}^{*} \mathrm{~L}^{*} \mathrm{H}-\%{ }^{9}$.

\section{2 Тональные конфигурации в вопросах с КФП}

Как и в контекстах с информационным фокусом, в контекстах с контрастным фокусом на последнем слове фразы была отмечена вариативность тональных конфигураций. Невозможным в контекстах КФП оказался только контур с единственным тональным акцентом на вопросительном слове (п. 3.1.1). Этот результат был ожидаем, поскольку использование такого варианта допускало бы деакцентуацию слова, находящегося в фокусе. Редким в контексте КФП также оказался вариант $\mathrm{H}^{*} \mathrm{~L}^{*} \mathrm{H}-\%$ (ИК-4 в системе Е. А. Брызгуновой; 3 примера).

Наиболее частотным для контекстов КФП в наших записях является контур с падением тона на слове - носителе фокуса, которому предшествует постепенное повышение ЧОТ от начального нейтрального среднего уровня на протяжении всей предшествующей фразы (рис. 5; ИК-2 в системе Е. А. Брызгуновой). При такой конфигурации остальные слова во фразе воспринимаются как деакцентуированные. Начало падения имеет непоздний тайминг, в связи с чем в рамках настоящей работы мы анализируем соответствующий ему на фонологическом уровне тональный акцент как $\mathrm{H}^{*}+\mathrm{L}$ и весь контур как $\mathrm{H}^{*}+\mathrm{L}$ L-\%. Таким образом, этот вариант отличается от варианта, описанного в п. 3.1.1, только локализацией тонального акцента, но не тональной конфигурацией.

\footnotetext{
${ }^{9}$ Отвечая на замечания анонимных рецензентов, касающиеся представленной здесь предварительной автосегментной интерпретации конфигурации тональных акцентов, соответствующих ИК-4, согласимся с тем, что данные, анализируемые в рамках настоящей статьи, позволяют судить лишь о контексте частного вопроса. Тем не менее мы не исключаем возможности распространения предложенной нами интерпретации и на другие типичные контексты ИК-4, представленные в традиционных описаниях русской просодии (включая односложные высказывания вроде $И-u^{4} ?$, в которых предъядерный акцент, вероятно, опускается в связи с ограниченностью сегментного материала, а падение тона происходит со среднего для говорящего начального уровня). Тщательное экспериментальное манипулирование количеством слогов в типичных контекстах ИК-4 (ср. $A^{4} \mathrm{mbl}^{4}$ ? и $A^{4}$ Константино ${ }^{4}$ польский?), по нашему мнению, способно продемонстрировать комплексный характер этой тональной конфигурации, требующий уточнения на основе новых экспериментальных и корпусных исследований.
} 
Вторым по частотности вариантом в контекстах КФП стал уже описанный в разделе 3.1.2 контур с двумя падениями тона $\mathrm{H}^{*}+\mathrm{L}(!) \mathrm{H}^{*+} \mathrm{L}$ L-\%. Судя по распределению двух наиболее частотных контуров, выбор между ними может быть связан с ритмикой фразы: в более коротких примерах с вопросительными словами когда и где (6 и 7 слогов во фразе соответственно) участники эксперимента чаще использовали контур с одним тональным акцентом $\mathrm{H}^{*}+\mathrm{L} \mathrm{L}-\%$, в то время как во фразах с вопросительным словом почему (11 слогов) - контур с двумя тональными акцентами $\mathrm{H}^{*}+\mathrm{L}$ $(!) \mathrm{H}^{*}+\mathrm{L}$ L-\%. Интересно, что «шляпный» контур, напротив, одинаково часто встречался в стимулах со всеми тремя вопросительными словами ( 9,10 и 10 раз в вопросах с когда, где и почему соответственно).

\section{3 Тональные конфигуращии в вопросах с КФС}

Результаты для вопросов с контрастным фокусом на субъекте имеют сходство с результатами для стимулов с контрастным фокусом на предикате. Наиболее частотным в записях был вариант контура с падением на слове - носителе фокуса и деакцентуацией остальных слов во фразе, см. рис. 6(a). Намного реже в записях встречались два других контура с низким пограничным тоном: $\mathrm{H}^{*+\mathrm{L}}\left(\right.$ !) $\mathrm{H}^{*}+\mathrm{L} \mathrm{L}-\%$ и $\mathrm{H}^{*} \mathrm{H}^{*+} \mathrm{L}$ L-\%.

Основным различием между контекстами КФП и КФС стало использование информантами во фразах с КФС контура с высоким пограничным тоном (H* L* H-\%; ИК-4 в системе Е. А. Брызгуновой). Пример такого употребления представлен на рис. 6(б); в разметке знак < при $\mathrm{H}^{*}$ означает, что тональный акцент ассоциирован с предшествующим слогом на фонологическом уровне, хотя фонетически реализуется отложенным пиком (см. использование этого символа для обозначения «позднего пика», например, в [Beckman et al. 2005]). Если в контекстах с КФП этот контур встретился только три раза, в контекстах с КФС с ним было зафиксировано 28 примеров, причем их количество оказалось неодинаковым в стимулах с разными вопросительными словами (18 примеров со словом когда, 9 - со словом где и только 1 - со словом почему). Возможным объяснением является то, что только в контекстах КФС с вопросительными словами когда и где субъект всегда был выражен существительным, а в примере с почему личным местоимением. Этот факт, однако, не объясняет обнаруженную разницу между стимулами с когда и где. Результаты для разных вопросительных слов подробнее обсуждаются ниже, в разделе 4.

\section{4 Статистический анализ факторов, оказывающих влияние на выбор контура}

Следует отметить, что в ходе анализа данных эксперимента возник ряд спорных случаев, в которых решение об отнесении примера к той или иной категории вызывало затруднения. В первую очередь трудности при анализе контуров были связаны с определением количества тональных акцентов 
во фразе, а именно, с наличием/отсутствием предъядерных ${ }^{10}$ тональных акцентов, в особенности акцентов на вопросительных словах во фразах с контрастным фокусом. На этих решениях основывается отнесение проанализированных примеров к группам с тональными конфигурациями $\mathrm{H}^{*}+\mathrm{L}$ $\mathrm{L}-\%, \mathrm{H}^{*} \mathrm{H}^{*}+\mathrm{L} \mathrm{L}-\%$ или $\mathrm{H}^{*}+\mathrm{L}(!) \mathrm{H}^{*}+\mathrm{L} \mathrm{L}-\%$.

Определение статуса предъядерных акцентов представляет собой не до конца решенную проблему, в том числе в языках с детально описанной просодией. В то время как одни исследования демонстрируют систематическую роль предъядерных акцентов в передаче элементов информационной структуры высказывания [Baumann et al. 2007; Féry, Kügler 2008; Braun, Biezma 2019], другие указывают на то, что эти акценты в некоторых случаях могут выполнять только ритмические [Calhoun 2010; Chodroff, Cole 2018], «орнаментальные» [Büring 2007] функции. Что касается русского языка, данные об инвентаре и функциях предъядерных тональных акцентов отсутствуют в существующих описаниях. При анализе контуров мы были вынуждены опираться на акустические критерии (характер изменения ЧОТ в районе ударных слогов, его выводимость на основе интерполяции между тональными целями), а также на восприятие перцептивной выделенности слов.

Тем не менее важно отметить, что описанные выше проблемы классификации касаются только различий между конфигурациями, завершающимися нисходящим движением тона. В рамках нашего анализа все эти контуры имеют важную общую черту: они содержат одинаковую конфигурацию из последнего (ядерного) тонального акцента фразы $\mathrm{H}^{*}+\mathrm{L}$ и пограничного тона L-\%, а различаются только наличием и формой предъядерных акцентов. На этом основании представляется возможным в рамках анализа объединить эти примеры в общую категорию «нисходящих» контуров. Напротив, единственного формального критерия, заключающегося в наличии/ отсутствии восходящего движения тона в конечной части последнего ударного слога фразы или сразу после него (ср., например, контуры (а) и (б) на рис. 6), достаточно, чтобы противопоставить «нисходящим» контурам категорию «восходящих» контуров, в которую войдут все примеры, проанализированные нами как содержащие тональную конфигурацию $\mathrm{H}^{*} \mathrm{~L} * \mathrm{H}-\%$. Таким образом, надежной представляется классификация экспериментальных данных по крайней мере на две категории: группа «нисходящих» контуров частного вопроса, с одной стороны (все контуры, оканчивающиеся конфигурацией $\left.\mathrm{H}^{*}+\mathrm{L} \mathrm{L}-\%\right)$, и единственный «восходящий» контур $\left(\mathrm{H}^{*} \mathrm{~L}^{*}\right.$ H-\%) - с другой. Именно на этом противопоставлении основывается представленный ниже статистический анализ данных эксперимента.

${ }^{10}$ Используемые в АМ-модели термины nuclear accent и prenuclear accent переводятся нами здесь как я дерный а кцент и предьядерный акце н т соответственно. В рамках настоящей работы под первым термином понимаются все тональные акценты (не пограничные тоны), являющиеся последними во фразе, под вторым термином - все непоследние тональные акценты. 
Для анализа факторов, оказывавших влияние на выбор контура частного вопроса участниками эксперимента, был использован метод регрессионного анализа с использованием $R$ [R Core Team 2018] и пакета lme 4 [Bates et al. 2015]. Построена бинарная логистическая модель с зависимой переменной «тип контура» (восходящий/нисходящий) и независимыми переменными «наличие частицы $а$ » (да/нет), «тип фокуса» (ИФ/КФП/ КФС), «вопросительное слово» (когда/где/почему), а также случайным свободным членом для информантов. Чтобы избежать проблем сходимости модели, число итераций было увеличено до 10000 с использованием оптимизатора $B O B Y Q A$. В соответствии с рекомендациями в [Levshina 2015: 272] предикторы были проверены на мультиколлинеарность с использованием функции vif пакета car [Fox, Weisberg 2019], значение фактора инфляции дисперсии во всех случаях составило менее 1,1 . Результаты статистического анализа представлены в Таблице $2^{11}$.

Согласно результатам регрессионного анализа, тип фокуса оказывал сильный эффект на выбор участниками эксперимента типа контура. Информанты чаще всего использовали восходящий контур в контекстах информационного фокуса, а реже всего - в контекстах с контрастным фокусом на глаголе. Примеры с контрастным фокусом на субъекте занимают промежуточное положение, при этом различия между каждой парой типов контекста оказались статистически значимыми $(p<.001)$.

Кроме того, статистически значимым $(p<.001)$ оказался эффект наличия инициальной частицы $a$. Информанты значительно чаще использовали восходящий контур, читая вслух фразы, содержащие это слово. Значение параметра «Отношения шансов» в Таблице 2 показывает, что шансы того, что фраза была произнесена с восходящим контуром, были выше в 4,48 раза, если эта фраза содержала инициальную частицу $a$ (по сравнению с отсутствием частицы во фразе).

Наконец, был обнаружен эффект вопросительного слова почему, статистически значимый $(p=.011)$, но существенно менее сильный по сравнению с двумя предыдущими. В вопросах с местоимением почему участники эксперимента гораздо реже использовали восходящий контур, чем в вопросах с когда и где. Между двумя последними группами стимулов статистически значимых различий обнаружено не было $(p=.96)$.

\section{4. Обсуждение и выводы}

Настоящее исследование представляло собой первую попытку экспериментального изучения вариативности интонации русских частновопросительных предложений. Данные эксперимента, проведенного при участии

\footnotetext{
${ }^{11}$ Файл с данными 345 наблюдений размещен в онлайн-приложении, см. https://osf.io/dgv3s.
} 
20 носителей русского языка, подтверждают имеющиеся в литературе сведения о разнообразии просодического оформления частного вопроса в современном русском языке. В результате анализа 345 записей фраз были выделены основные тональные конфигурации, использовавшиеся информантами; для каждой конфигурации была предложена фонологическая интерпретация в рамках АМ-модели.

Прежде чем перейти к краткому обсуждению каждой конфигурации, необходимо сделать важное обобщение, касающееся просодической выделенности вопросительных слов. В проанализированном материале в у с л в иях ин формационного фокуса местоименные вопросительные слова где, когда и почему всегда выступали носителями предъядерного или (реже) ядерного тонального акцента. При этом факультативная деакцентуация вопросительных слов была возможной только в контекстах корректирующего фокуса. Таким образом, с точки зрения просодической типологии русский язык нельзя безоговорочно отнести ни к одному из двух типов языков, выделенных в работе [Ladd 2008: 226-230] по признаку того, какое слово выступает носителем ядерного тонального акцента в коротких частных вопросах. В своей классической работе Р. Лэдд выделяет два возможных сценария: с одной стороны, в таких языках, как, например, румынский, венгерский и греческий, ядерный тональный акцент в коротких частных вопросах всегда реализуется на вопросительном местоимении; с другой стороны, в таких языках, как, например, английский и итальянский, носитель ядерного тонального акцента выбирается по тем же правилам, что и в повествовательном предложении. Как показали наши данные, в русском языке в контексте информационного фокуса возможны оба сценария. Сведения об акцентуации русских вопросительных местоимений, безусловно, также представляют интерес с точки зрения окончательно не решенного в синтаксической теории вопроса о фокусной интерпретации этих языковых единиц. Не считая возможным подробно обсуждать столь фундаментальные вопросы синтаксиса на основании данных настоящего эксперимента, укажем на недавний подробнейший анализ этой проблематики в работе [Bocci et al. 2021], авторы которой, анализируя распределение тональных акцентов в различных структурах прямого и косвенного итальянского частного вопроса, предостерегают от прямолинейного связывания просодической выделенности с фокусом в этом типе вопросительных предложений.

Итак, согласно нашему анализу, частотным в речи носителей русского языка является вариант частного вопроса с падением тона на вопросительном слове и деакцентуацией остальной части предложения. В том случае, если одно из слов фразы (в нашем материале это могло быть существительное или местоимение в роли субъекта, а также глагол в роли предиката) является носителем контрастного фокуса, такой же тональный акцент может быть ассоциирован с этим словом, сопровождаясь деакцентуацией остальных слов во фразе. В обоих случаях мы интерпретируем тональную 
конфигурацию как $\mathrm{H}^{*}+\mathrm{L}$ L-\%. Такие результаты в целом согласуются с данными наиболее распространенного традиционного описания русской интонации, системы Е. А. Брызгуновой, в которой эта конфигурация получила название ИК-2.

Наряду с контуром $\mathrm{H}^{*}+\mathrm{L}$ L-\%, предполагающим деакцентуацию всех слов во фразе, кроме слова - носителя фразового ударения, в данных встретился контур с двумя нисходящими движениями тона: на вопросительном слове и на субъекте или предикате. Оба падения тона характеризуются непоздним таймингом, в связи с этим мы анализируем их как репрезентации тонального акцента $\mathrm{H}^{*}+\mathrm{L}$. Кроме того, второй тональный максимум регулярно имеет значительно меньшую частоту по сравнению с первым, что в рамках АМ-модели, по всей видимости, должно описываться как применение правила даунстепа. Использование такого контура в русском частном вопросе также отмечается не впервые, ранее оно было описано в [Кодзасов 2009: 108].

Нередкой в данных эксперимента оказалась тональная конфигурация H* H*+L L-\%, так называемый «шляпный» контур (ИК-5 в системе Е. А. Брызгуновой), который в работах С. В. Кодзасова и Н. Д. Светозаровой характеризовался как основной нейтральный способ оформления частного вопроса. Первый тональный акцент этого контура всегда ассоциирован с вопросительным словом и фонетически реализуется подъемом ЧОТ, максимум тона достигается в конце ударного слога, после чего не происходит резкого падения тона. Описанная конфигурация оказалась возможной во всех экспериментальных условиях, в том числе как при информационном, так и при контрастном фокусе.

Несмотря на то что описанные выше тональные конфигурации противопоставлены на фонологическом уровне, интерпретация их фонетических репрезентаций в некоторых случаях представляет собой трудноразрешимую задачу, в конечном счете основывающуюся на определении наличия/ отсутствия и формы предъядерного тонального акцента во фразе. Чтобы эти решения не оказывали влияния на статистический анализ, в рамках настоящего исследования мы объединили эти варианты в группу «нисходящих» контуров на основании того, что все они содержат одинаковую конфигурацию ядерного тонального акцента и пограничного тона: H*+L L-\%.

Проблем классификации не возникает в случае с другой тональной конфигурацией, оказавшейся частотной в полученных записях: контуром, который в системе Е. А. Брызгуновой называется ИК-4. На основании фонетических данных мы предварительно анализируем этот контур как последовательность акцентов $\mathrm{H}^{*} \mathrm{~L} * \mathrm{H}-\%$, причем тональный акцент $\mathrm{H}^{*}$ всегда был ассоциирован с ударным слогом вопросительного слова, a L* - с ударным слогом слова, выступающего в роли субъекта или предиката. В записях не встретились примеры с L* на вопросительном слове, охарактеризованные Е.А. Брызгуновой как варианты «назидательного» частного вопроса. 
Полученные результаты, касающиеся вариативности просодии русских частных вопросов, обнаруживают сходство с данными некоторых экспериментальных исследований, посвященных другим языкам. В наших записях 74,5 \% частных вопросов были произнесены участниками эксперимента с «нисходящей» интонацией. Для сравнения: доля частных вопросов, произнесенных с низким пограничным тоном, в эксперименте [Repp 2019] на материале немецкого языка составила две трети, в [Hirschberg 2000] на материале английского - 83,8 \% при чтении и 62,2 \% в спонтанной речи, в [Hedberg et al. 2004] также на материале английского - $82 \%$.

Дизайн эксперимента позволил проверить гипотезы о влиянии на выбор носителями языка типа контура двух факторов: наличия контрастного фокуса и инициальной частицы $a$.

Как и ожидалось, было обнаружено статистически значимое влияние типа фокуса на выбор контура. Сталкиваясь с обусловленной контекстом диалога необходимостью маркировать при помощи просодии контрастный фокус на предикате или субъекте, участники эксперимента значительно чаще выбирали нисходящие контуры. Эти результаты подтверждают имеющееся в литературе представление о том, что в русском языке основным способом просодического выделения слова во фразе является нисходящее движение тона (см. данные о передвижении центра ИК-2 в модели Е. А. Брызгуновой). Тем не менее в наших данных в контекстах с контрастным фокусом на субъекте информанты нередко использовали восходящий контур $\mathrm{H}^{*} \mathrm{~L}^{*} \mathrm{H}-\%$, в котором просодически выделенное слово маркируется низким тональным акцентом. При этом в контекстах с контрастным фокусом на предикате акцент $\mathrm{L}^{*}$ использовался крайне редко. Возможное объяснение заключается в том, что в проанализированных фразах локализации тонального акцента на непоследнем слове фразы оказывается достаточно, чтобы выразить контрастный фокус, вне зависимости от того, какой тональный акцент выбран - $\mathrm{H}^{*}+\mathrm{L}$ или $\mathrm{L}^{*}$. Напротив, локализация тонального акцента на последнем слове фразы (в нашем материале регулярно становившемся носителем ядерного акцента в контекстах ИФ) создает условия для омонимии между ИФ и КФП. Вероятно, с целью избежать этой неоднозначности участники эксперимента почти не использовали конфигурацию L* H-\% на последнем слове фразы в контекстах КФП. Таким образом, «восходящая» конфигурация тонального акцента и пограничного тона, ассоциированная с последним словом фразы, выступает в роли надежного сигнала информационного фокуса, при этом «нисходящая» может использоваться как при ИФ, так и при КФП.

Если влияние информационной структуры на выбор тональных акцентов широко распространено типологически, то обнаруженный нами эффект инициальной частицы $a$, безусловно, является специфическим для русской просодии. Анализ распределения двух вариантов показал, что участники эксперимента значительно чаще выбирали «восходящую» тональную конфигурацию $\mathrm{H}^{*} \mathrm{~L}^{*} \mathrm{H}-\%$, если во фразе присутствовало это слово. 
Следует оговориться, что, поскольку в нашем эксперименте в качестве метода элицитации использовалось чтение диалогов вслух, полученные данные позволяют распространять выводы только на этот тип речевой деятельности носителей языка. Действительно, поскольку дизайн эксперимента вынуждал участников произносить частные вопросы с частицей $a$, ошибкой было бы предполагать, что полученные данные могут быть безусловно распространены также на спонтанно порождаемую речь. В отличие от условий нашего эксперимента, в условиях порождения спонтанной речи говорящий волен выбирать, употреблять или нет частицу $а$ в частном вопросе. Тем не менее наличие столь сильной корреляции между использованием в частном вопросе инициальной частицы и конфигурации $\mathrm{H}^{*} \mathrm{~L}^{*}$ Н-\% требует объяснения.

Наиболее вероятной интерпретацией этой зависимости является то, что в данном случае оба наблюдаемых признака обусловлены единой причиной, а именно, обе языковые единицы служат факультативными средствами выражения одного и того же значения. Вероятный кандидат, по нашему мнению, - приписываемое в литературе частице $a$ значение «подключения $\langle\ldots\rangle$ высказывания к какому-то предтексту, 〈..〉 его включенность в более крупную коммуникативную единицу» [Зализняк, Микаэлян 2018б: 337]; ср. регулярно отмечавшиеся для ИК-4 функции выражения «сопоставительных отношений с предшествующим предложением» [Брызгунова 1980a: 114]; также у Е. А. Брызгуновой об ИК-4 в вопросах: «Связь с предшествующим наиболее очевидно проявляется в предложениях с местоименным словом...» [Брызгунова 1980б: 401] ${ }^{12}$

Отметим, однако, что в нашем материале параметр «включенность в ряд реплик» на формальном уровне выступал в качестве константы: во всех диалогах частному вопросу обязательно предшествовал другой вопрос; «неконтекстуализированные» частные вопросы в настоящей работе не рассматривались. В качестве примера такого инициирующего коммуникацию вопроса, не имеющего предтекста, но содержащего частицу $a$, можно привести начинающую диалог с продавцом фразу «А сколько стоит этот пирог?..» [Николаева 1997]. Несмотря на наличие инициального $a$, использование тонального акцента L* и пограничного тона Н-\% в этом контексте представляется маловероятным; таким образом, принимая анализ частицы как «интимизатора» или «квазитематизатора», мы должны допускать возможное отсутствие такой функции у обычно сопровождающей ее тональной конфигурации. Безусловно, в целях дальнейшего изучения взаимодействия между просодией, синтаксисом и семантикой представляет интерес экспериментальное манипулирование не только наличием/от-

\footnotetext{
12 Другая возможная «кандидатура» на роль общего элемента значения - сема контраста, очевидно, имеющаяся у $a$, но также выделяемая в [Янко 2008] как «инвариантное значение ИК-4» (ср. также «инвариантный параметр соотношения», предлагаемый для ИК-4 в [Безяева 2002]).
} 
сутствием $a$, но и типами контекстов, в которых употребляются содержащие эту частицу частные вопросы.

Наконец, следует обсудить третий статистически значимый эффект, который был, вопреки ожиданиям, обнаружен в результате регрессионного анализа: фразы с вопросительным словом почему реже произносились с восходящим контуром по сравнению с фразами, содержавшими вопросительные слова где и когда. В разделе 3.5 эта зависимость была условно названа «эффектом вопросительного слова», однако в действительности стимулы, различавшиеся вопросительными словами, также отличались еще как минимум по трем признакам: количеству слогов во фразе (вопросы с почему были существенно длиннее, чем вопросы с где и когда; 11 против 7 и 6 слогов соответственно), отсутствию/наличию отрицания при глаголе и отсутствию/наличию замены существительного на местоимение в контекстах КФС. Таким образом, обнаруженный эффект может быть связан с любым из этих факторов. Невозможность разграничить эффекты перечисленных факторов следует отнести к недостаткам дизайна эксперимента, которые должны быть учтены при планировании новых исследований.

В заключение отметим, что результаты эксперимента, подтверждая вариативность интонационного оформления частного вопроса в русском языке и выделяя по крайней мере два ее возможных источника, безусловно, демонстрируют необходимость дальнейшего изучения описанных явлений. $\mathrm{C}$ нашей точки зрения, наибольший интерес для будущих исследований представляют два основных направления. С одной стороны, новые экспериментальные и корпусные данные необходимы для того, чтобы углубить понимание закономерностей фонетической реализации тональных конфигураций, характерных для частного вопроса. В частности, в экспериментальной проверке нуждается анализ предъядерных тональных акцентов, описанных в настоящей работе как $\mathrm{H}^{*}$ и $\mathrm{H}^{*}+\mathrm{L}$; формального описания требуют условия применения правила даунстепа; необходимы сведения о тайминге высоких пограничных тонов в русском языке. Эти и другие фонетические данные позволят уточнить предложенную в статье предварительную фонологическую интерпретацию наблюдаемых явлений и ее отражение в ТоВI-транскрипции русской интонации. С другой стороны, детальное понимание фонетической реализации противопоставленных на фонологическом уровне контуров русских частных вопросов сделает возможным проведение перцептивных экспериментов, направленных на изучение функциональной нагрузки просодических вариантов. Экспериментальные данные о восприятии этих тональных конфигураций позволят уточнить устоявшиеся в литературе утверждения о прагматической маркированности некоторых контуров частных вопросов, в настоящий момент основывающиеся главным образом на интуиции исследователей и ранее не проверявшиеся методами экспериментальной фонетики. 


\section{Приложение}

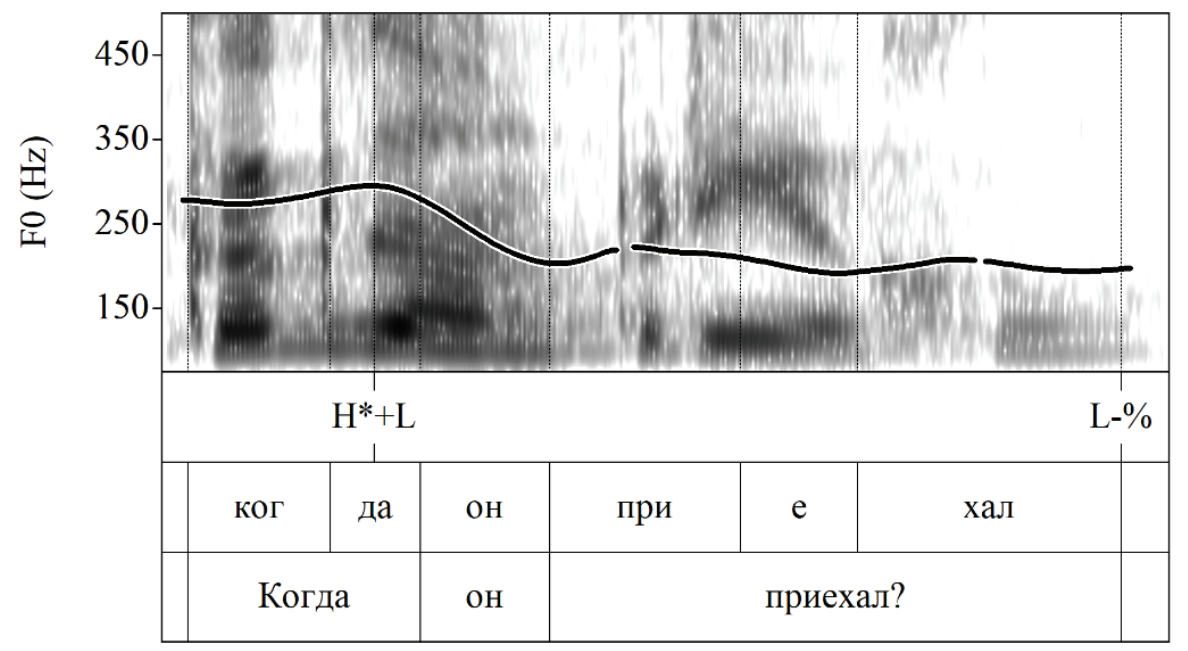

Puc. 1. Спектрограмма и контур ЧОТ фразы Когда он приехал? в произношении диктора 10

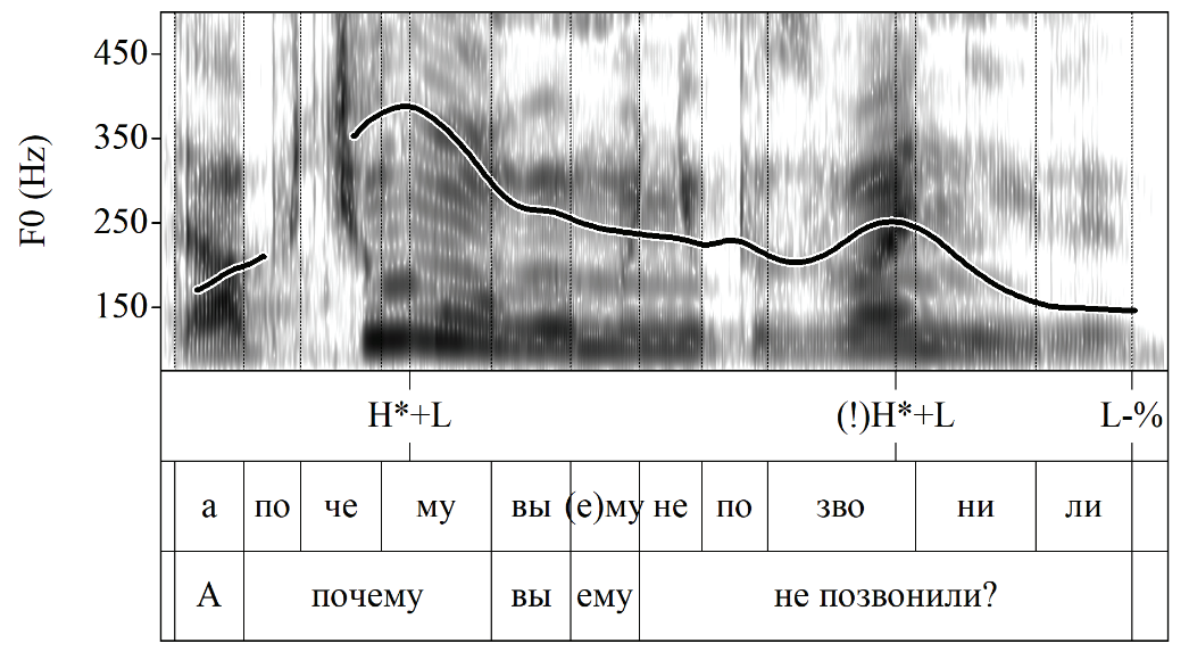

Рис. 2. Спектрограмма и контур ЧОТ фразы $A$ почему вы ему не позвонили? в произношении диктора 15 


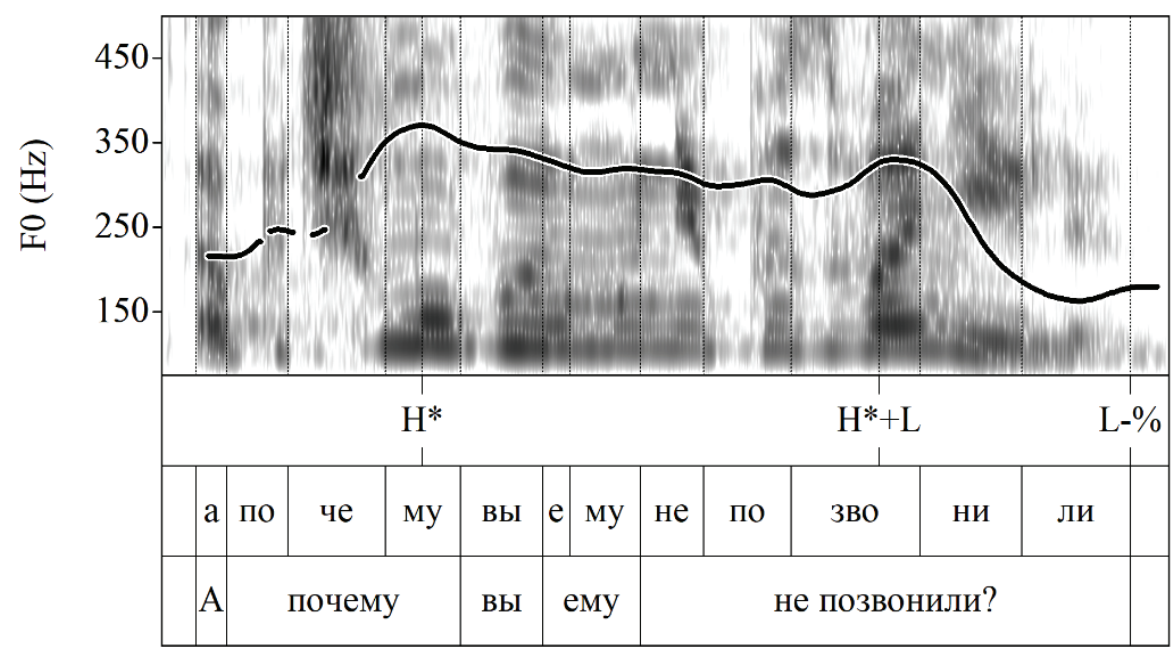

Рис. 3. Спектрограмма и контур ЧОТ фразы А почему вы ему не позвонили? в произношении диктора 18

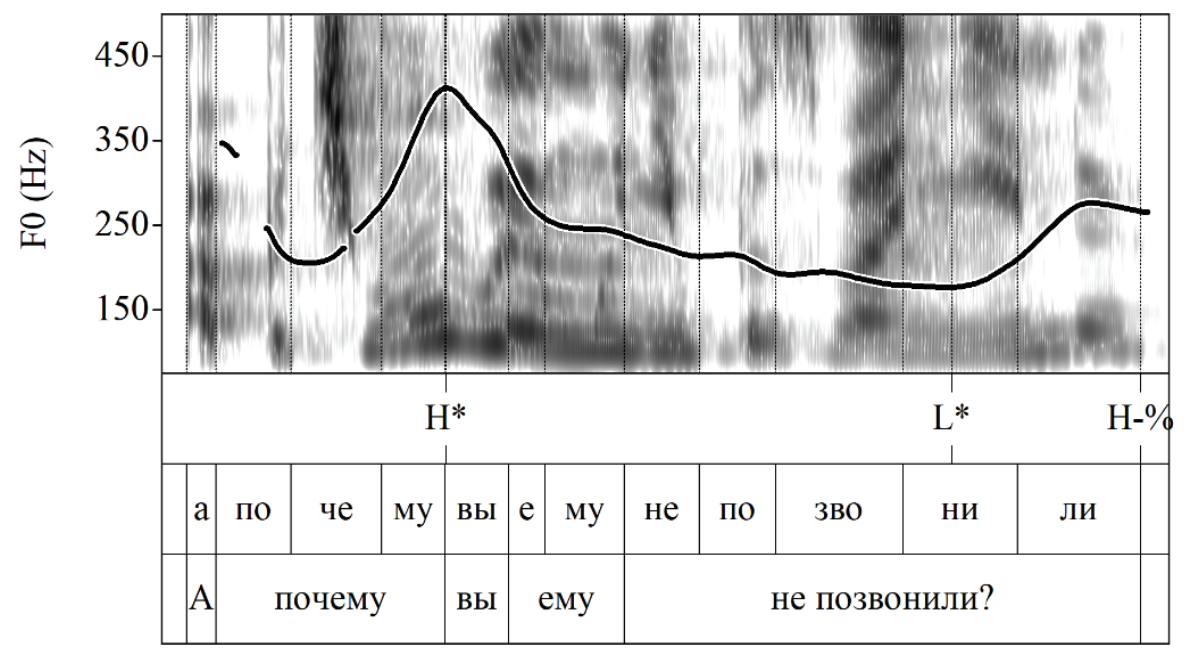

Puc. 4. Спектрограмма и контур ЧОТ фразы $A$ почему вы ему не позвонили? в произношении диктора 1 


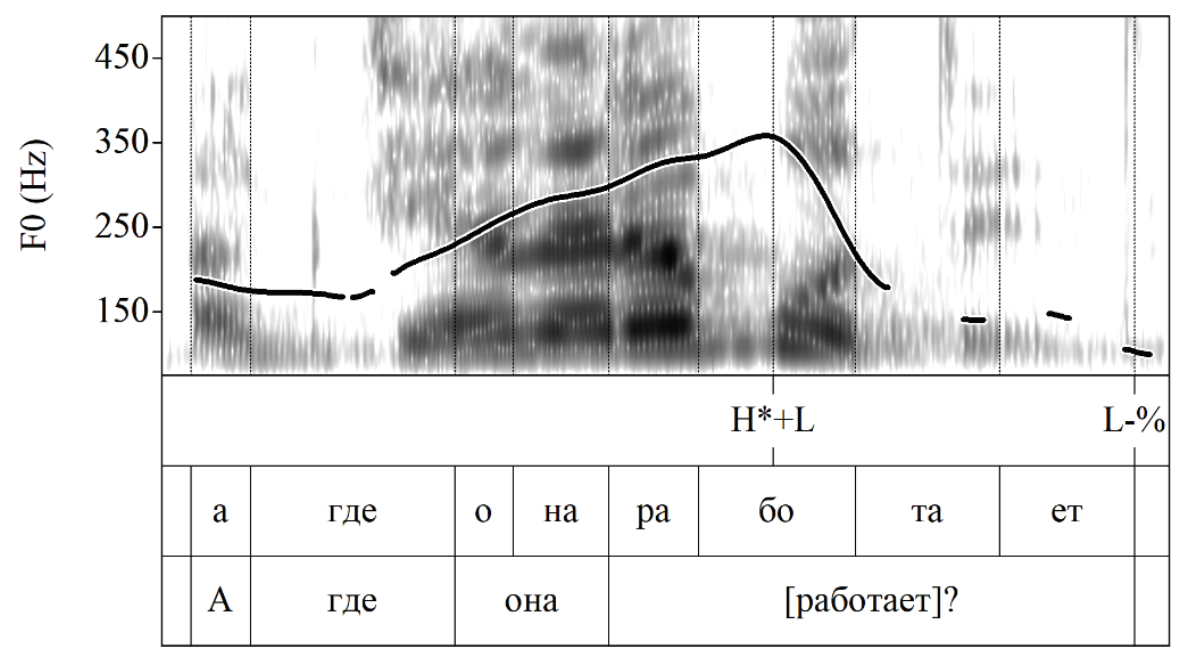

Puc. 5. Спектрограмма и контур ЧОТ фразы $A$ где она [paботает]? в произношении диктора 12 

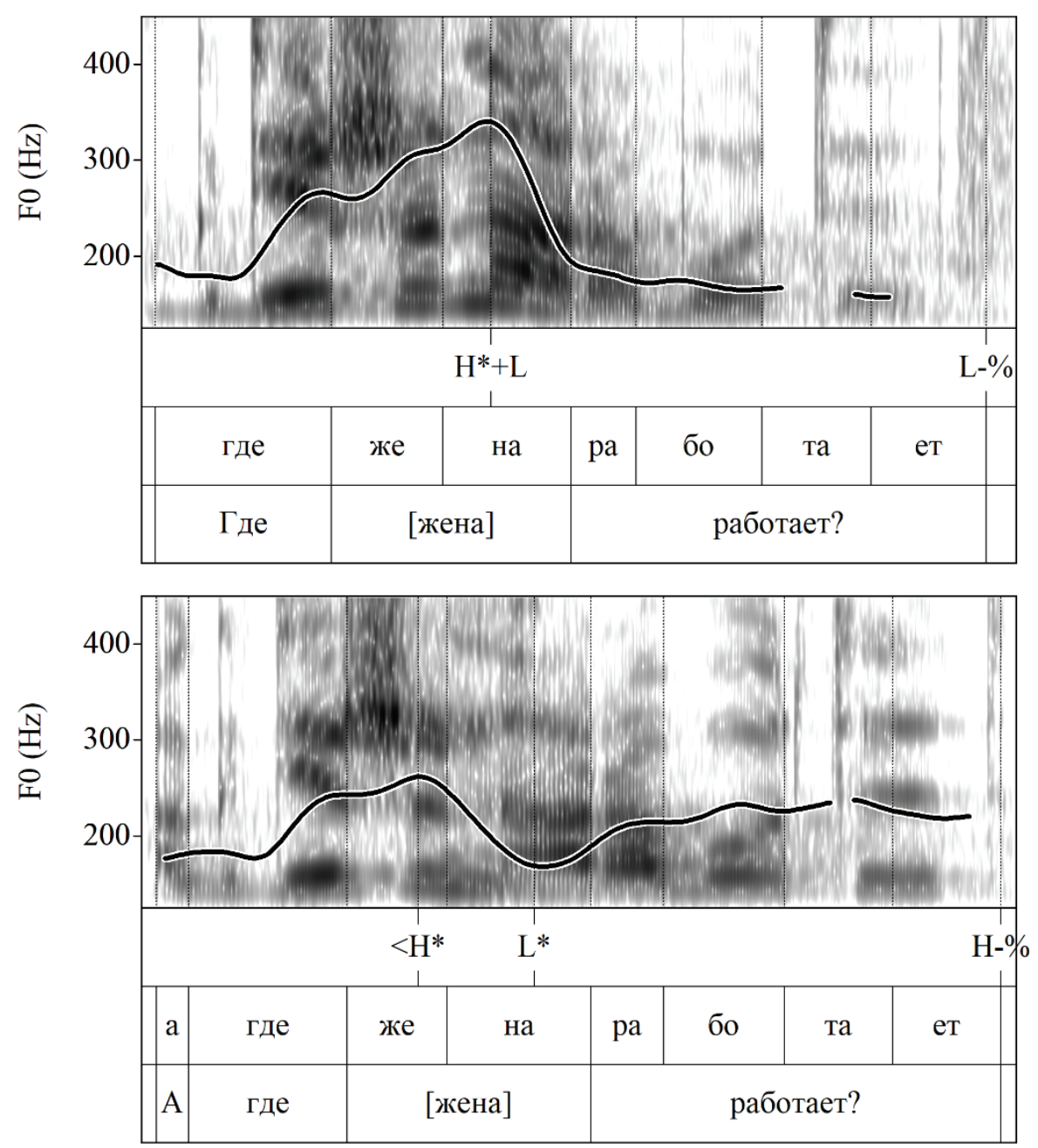

Puc. 6. Спектрограммы и контуры ЧОТ фраз (а) Где [жена] работает? и (б) $A$ где [жена] работает?, обе — в произношении диктора 18 
Таблища 1

Результаты классификации контуров фраз, полученных в ходе эксперимента. ИФ - информационный фокус, КФП - контрастный фокус на предикате, КФС - контрастный фокус на субъекте

\begin{tabular}{|c|c|c|c|c|c|c|c|}
\hline \multirow{2}{*}{ 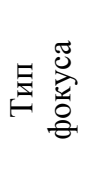 } & \multirow{2}{*}{ 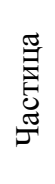 } & \multirow{2}{*}{ 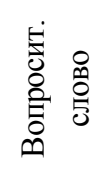 } & \multicolumn{3}{|c|}{ Нисходящие контуры } & \multirow{2}{*}{\begin{tabular}{|c} 
Восходящ. \\
контур
\end{tabular}} & \multirow{2}{*}{ O্ঠ } \\
\hline & & & $\mathrm{H}^{*+\mathrm{L} \mathrm{L}-\%}$ & $\begin{array}{c}\mathrm{H}^{*+\mathrm{L}} \\
(!) \mathrm{H}^{*+\mathrm{L} \mathrm{L}} \mathrm{L}-\%\end{array}$ & $\begin{array}{c}\mathrm{H}^{*} \mathrm{H}^{*+\mathrm{L}} \\
\mathrm{L}-\%\end{array}$ & & \\
\hline \multirow[t]{6}{*}{ ИФ } & \multirow[t]{3}{*}{-} & где & 4 & 2 & 2 & 12 & 20 \\
\hline & & когда & 11 & 3 & 2 & 4 & 20 \\
\hline & & почему & 2 & 11 & 1 & 5 & 19 \\
\hline & \multirow[t]{3}{*}{ A } & где & 4 & 0 & 3 & 13 & 20 \\
\hline & & когда & 4 & 3 & 1 & 11 & 19 \\
\hline & & почему & 0 & 2 & 5 & 12 & 19 \\
\hline \multirow[t]{6}{*}{ КФП } & \multirow[t]{3}{*}{-} & где & 13 & 0 & 6 & 0 & 19 \\
\hline & & когда & 13 & 4 & 3 & 0 & 20 \\
\hline & & почему & 0 & 15 & 5 & 0 & 20 \\
\hline & \multirow[t]{3}{*}{ A } & где & 14 & 1 & 4 & 1 & 20 \\
\hline & & когда & 11 & 2 & 6 & 0 & 19 \\
\hline & & почему & 0 & 10 & 5 & 2 & 17 \\
\hline \multirow[t]{6}{*}{ КФС } & \multirow[t]{3}{*}{-} & где & 16 & 0 & 4 & 0 & 20 \\
\hline & & когда & 8 & 0 & 2 & 8 & 18 \\
\hline & & почему & 13 & 3 & 3 & 0 & 19 \\
\hline & \multirow[t]{3}{*}{ A } & где & 7 & 1 & 3 & 9 & 20 \\
\hline & & когда & 6 & 0 & 1 & 10 & 17 \\
\hline & & почему & 13 & 3 & 2 & 1 & 19 \\
\hline \multicolumn{3}{|c|}{ Всего } & 139 & 60 & 58 & 88 & 345 \\
\hline \multicolumn{3}{|c|}{ Всего, \% } & 40,29 & 17,39 & 16,81 & 25,51 & 100 \\
\hline
\end{tabular}


Результаты статистического анализа влияния трех факторов на выбор типа интонационного контура участниками эксперимента

\begin{tabular}{|c|c|c|c|}
\hline \hline \multicolumn{5}{|c|}{ Тон: восходящий/нисходящий } \\
\hline Предикторы & Отношения шансов & $95 \%$ доверит. интервалы & $p$ \\
\hline \hline (Intercept) & 0.15 & $0.06-0.37$ & $<0.001$ \\
\hline частица: А & 4.48 & $2.31-8.68$ & $<0.001$ \\
\hline фокус: КФП & 0.05 & $0.01-0.18$ & $<0.001$ \\
\hline фокус: ИФ & 3.99 & $2.03-7.83$ & $<0.001$ \\
\hline вопр. слово: когда & 1.02 & $0.49-2.12$ & 0.961 \\
\hline вопр. слово: почему & 0.36 & $0.16-0.79$ & 0.011 \\
\hline \hline \multicolumn{5}{|c|}{ Случайные эффекты } & 345 \\
\hline \hline$\sigma^{2}$ & 3.29 & Всего наблюдений & $3.483 /$ \\
\hline$\tau_{\text {0о информант }}$ & 1.23 & Предельн. $\mathrm{R}^{2} /$ & 0.624 \\
\hline ІСС & 0.27 & Условн. ${ }^{2}$ & 285.225 \\
\hline Количество информантов & 20 & АІС & \\
\hline \hline
\end{tabular}

\section{Лит т р а т ур а}

Безяева 2002 - Е. Г. Б е з я е в а. Семантика коммуникативного уровня звучащего языка. М.: Изд-во Моск. ун-та, 2002.

Брызгунова 1963 - Е. А. Бр ы з г у н о в а. Практическая фонетика и интонация русского языка. М.: Изд-во Моск. ун-та, 1963.

Брызгунова 1980a - Е. А. Б р ы з г у н о в а. Интонация // Русская грамматика. Т. 1: фонетика, фонология, ударение, интонация, словообразование, морфология / Под ред. Н. Ю. Шведовой. М.: Наука, 1980.

Брызгунова $1980 б$ - Е. А. Б р ы з г у н о в а. Средства выражения неизвестного в вопросе (взаимодействие лексики, контекста и интонации) // Русская грамматика. Т. 2: синтаксис / Под ред. Н. Ю. Шведовой. М.: Наука, 1980.

Зализняк, Микаэлян 2018a - А. 3 а л и з н я к, И. М и к а эл ян. Союз $a / / \mathrm{Ce}-$ мантика коннекторов: контрастивное исследование / О. Ю. Инькова (ред.). М.: Торус Пресс, 2018. С. 24-79.

Зализняк, Микаэлян $2018 б-$ А. 3 ал и зн як, И. М и ка элян. Русское $a$ : опыт интегрального описания // Russian Linguistics. 42. 2018. С. 321-344.

Игараси 2002 - Й. И г а р а с и. Так называемая «нейтрализация интонации» фонологическое описание русской интонации // Бюллетень Японской ассоциации русистов. 34. 2002. С. 15-21. 
Йокояма 2003 - О. Й о к я ма. Нейтральная и ненейтральная интонация в русском языке: автосегментная интерпретация системы интонационных конструкций // Вопросы языкознания. 2003. № 5. С. 99-122.

Кодзасов 1985 - С. В. К о д з а с о в. Интонация вопросительных предложений: форма и функции // Диалоговое взаимодействие и представление знаний / А. С. Нариньяни (ред.). Новосибирск: ВЦ СО АН СССР, 1985. С. 48-63.

Кодзасов 1996 - С. В. К о дз а с о в. Комбинаторная модель фразовой просодии // Просодический строй русской речи / Т. М. Николаева (ред.). М.: Ин-т рус. яз. РАН, 1996. С. 85-121.

Кодзасов 2009 - С. В. К о дз а с о в. Исследования в области русской просодии. М.: Языки славянских культур, 2009.

Николаева 1982 - Т. М. Н и к о л а е в а. Семантика акцентного выделения. М.: Наука, 1982.

Николаева 1997 - Т. М. Н и к о л а е в а. Сочинительные союзы $a, н o, u:$ история, сходства и различия // Славянские сочинительные союзы / Т. М. Николаева (ред.). М.: Ин-т славяноведения РАН, 1997. С. 3-24.

Оде 2007 - С. О д е. Заметки о понятии тональный акиент на примере русского языка // Проблемы фонетики V / Р. Ф. Касаткина (ред.). М.: Наука, 2007. С. 237-249.

Подлесская 2018 - В. И. П о дл е с с кая. «А у нас в квартире газ! А у вас?»: конструкции с союзом А по данным просодически размеченного корпуса // Компьютерная лингвистика и интеллектуальные технологии: По материалам ежегодной международной конференции «Диалог» / В. П. Селегей (ред.). М.: Издательский центр РГГУ, 2018. С. 601-618.

Фужерон 1997 - И. Ф у же р он. О некоторых особенностях русских сочинительных союзов. Союзы $u$ и $a$, союзы $a$ и но // Славянские сочинительные союзы / Т. М. Николаева (ред.). М: Ин-т славяноведения РАН, 1997. С. 25-35.

Шкапа 2013 - М. В. Ш к а п а. Клефт в ирландском языке: к типологии клефта и тетических предложений // Вопросы языкознания. 2013. № 5. С. 89-105.

Янко 2008 - Т. Е. Я н к о. Интонационные стратегии русской речи в сопоставительном аспекте. М.: Языки славянских культур, 2008.

Arvaniti, Baltazani 2005 - A. A rva n i ti, M. B a 1 t a z a n i. Intonational Analysis and Prosodic Annotation of Greek Spoken Corpora // Prosodic Typology: The Phonology of Intonation and Phrasing / Sun-Ah Jun (ed.). Oxford: Oxford University Press, 2005. P. 84-117.

Arvaniti, Ladd 2009 - A. A rva n it i, D. R. L a d d. Greek wh-questions and the phonology of intonation // Phonology. 26. 2009. P. 43-74.

Baltazani et al. 2020 - M. B a $1 \mathrm{t}$ a z a ni, S. Gry 11 i a, A. A rvanit i. The Intonation and Pragmatics of Greek wh-Questions // Language and Speech. 63 (1). 2019. P. 56-94.

Bates et al. 2015 - D. B a te s, M. M a e chl e r, B. B o lke r, S. W a lk e r. Fitting Linear Mixed-Effects Models Using lme4 // Journal of Statistical Software. 67 (1). 2015. P. 1-48.

Baumann 2012 - S. B a u m a n n. The Intonation of Givenness: Evidence from German. Berlin: De Gruyter, 2012.

Baumann et al. 2007 - S. B a u mann, J. B e cker, M. Grice, D. Mücke. Tonal and articulatory marking of focus in German // 16th International Congress of Phonetic Sciences / J. Trouvain, W. J. Barry (eds.). 2007. P. 1029-1032. 
Beckman et al. 2005 - M. E. B e ckman, J. Hirschberg, S. S hat tuck$\mathrm{Hufn}$ a g e l. The Original ToBI System and the Evolution of the ToBI Framework // Prosodic Typology: The Phonology of Intonation and Phrasing / Sun-Ah Jun (ed.). Oxford: Oxford University Press, 2005. P. 9-54.

Beckman, Pierrehumbert 1986 - M. E. B e c k m a n, J. P i e r r e h u m b e r t. Intonational Structure in Japanese and English // Phonology Yearbook III. Cambridge: Cambridge University Press, 1986. P. 15-70.

Bocci et al. 2021 - G. B o c c i, V. B i a n c h i, S. Cru s c h in a. Focus in wh-questions // Natural Language and Linguistic Theory. 39. 2021. P. 405-455.

Boersma, Weenink 2019 - P. B o er s m a, D. W e e n in k. Praat: doing phonetics by computer [Computer program]. Version 6.1.08. URL: http://www.praat.org/ (дата обращения: 05.12.2021)

Braun, Biezma 2019 - B. B r a u n, M. B i e z ma. Prenuclear L*+H Activates Alternatives for the Accented Word // Frontiers in Psychology. 10. 2019. P. 1993.

Breen et al. 2010 - M. B reen, E. Fe dorenko, M. Wagner, E. Gibson. Acoustic correlates of information structure // Language and cognitive processes. 25. 2010. P. 1044-1098.

Büring 2007 - D. B ü r in g. Semantics, Intonation, and Information Structure // The Oxford Handbook of Linguistic Interfaces / G. Ramchand and C. Reiss (eds.). Oxford: Oxford University Press, 2007. P. 445-474.

Calhoun 2010 - S. C a 1 h o u n. The centrality of metrical structure in signaling information structure: A probabilistic perspective // Language. 86. 2010. P. 1-42.

Chen 2012 - A. Chen. Shaping the intonation of WH-questions: Information structure and beyond // Questions: Formal, functional and interactional perspectives / J. P. de Ruiter (ed.). Cambridge: Cambridge University Press, 2012. P. 146-164.

Chodroff, Cole 2018 - E. C h o d r o ff, J. C o l e. Information structure, affect, and prenuclear prominence in American English // Proceedings of Interspeech 2018. P. $1848-1852$.

Féry, Ishihara 2016 - C. F é ry, S. I s h i h a r a. Introduction // The Oxford Handbook of Information Structure / C. Féry, S. Ishihara (eds.). Oxford: Oxford University Press, 2016.

Féry, Kügler 2008 - C. F é r y, F. K ü g l e r. Pitch accent scaling on given, new and focused constituents in German // Journal of Phonetics. 36. 2008. P. 680-703.

Fox, Weisberg 2019 - J. F o x, S. W e i s b e r g. An $\{R\}$ Companion to Applied Regression, Third Edition. Thousand Oaks: SAGE Publishing, 2019.

Grice et al. 2005 - M. Gri c e, S. B a u m a n n, R. B e n z m ü 11 e r. German Intonation in Autosegmental-Metrical Phonology // Prosodic Typology: The Phonology of Intonation and Phrasing / Sun-Ah Jun (ed.). Oxford: Oxford University Press, 2005. P. 55-83.

Grice et al. 2000 - M. Grice, D. R. Ladd, A. Arvaniti. On the Place of Phrase Accents in Intonational Phonology // Phonology. 17. 2000. P. 143-185.

Gryllia et al. 2018 - S. Gryllia, M. B altazani, A. Arvaniti. The role of pragmatics and politeness in explaining prosodic variability // Proceedings of the 9th International Conference on Speech Prosody / K. Klessa, J. Bachan, A. Wagner, M. Karpiński, D. Śledziński (eds.). Poznan, 2018. P. 158-162.

Gryllia et al. 2019 - S. Gry lli a, M. B a ltazani, A. A rvaniti. Evidence for the compositionality of tunes and intonational meaning // Proceedings of the 19th Inter- 
national Congress of Phonetic Sciences / S. Calhoun, P. Escudero, M. Tabain, P. Warren (eds.). Melbourne, 2019. P. 2841-2845.

Gussenhoven 2004 - C. G u s s e n h o v e n. The Phonology of Tone and Intonation. Cambridge: Cambridge University Press, 2004.

Gussenhoven 2008 - C. Gu s s e n h o v e n. Types of Focus in English // Topic and Focus. Studies in Linguistics and Philosophy, vol. 82 / C. Lee, M. Gordon, D. Büring (eds.). Dordrecht: Springer, 2008. P. 83-100.

Haan 2001 - J. H a a n. Speaking of Questions: An Exploration of Dutch Question Intonation. Utrecht: LOT, 2001.

Hedberg, Sosa 2002 - N. Hedberg, J. M. S o s a. The Prosody of Questions in Natural Discourse // Speech Prosody 2002. Aix-en-Provence, 2002. P. 375-378.

Hedberg et al. 2004 - N. Hedberg, J. M. S o s a, L. F a d d e n. Meanings and Configurations of Questions in English // Speech Prosody 2004 / B. Bel, I. Marlien (eds.). Nara, 2004. P. 309-312.

Hirschberg 1989 - J. Hirschberg. Distinguishing Questions by Contour in Speech Recognition Tasks // Speech and Natural Language: Proceedings of a Workshop Held at Cape Cod, Massachusetts, October 15-18. 1989 P. 22-33.

Hirschberg $2000-$ J. H ir s c h b e r g. A Corpus-Based Approach to the Study of Speaking Style // Prosody: Theory and Experiment / M. Horne (ed.). Dordrecht: Springer, 2000. P. 335-350.

Igarashi 2006 - Y. Ig a r a s h i. Intonational Patterns in Russian Interrogatives Phonetic Analyses and Phonological Interpretations // Prosody and Syntax: Crosslinguistic perspectives / Y. Kawaguchi, I. Fónagy, T. Moriguchi (eds.). Amsterdam: John Benjamins Publishing, 2006. P. 175-196.

Igarashi 2008 - Y. I g a r a s h i. Russian interrogatives and intonational categories // The Discourse Potential of Underspecified Structures / A. Steube (ed.). Berlin: De Gruyter, 2008. P. 227-269.

Jun 2005 - Sun-Ah Jun (ed.). Prosodic Typology: The Phonology of Intonation and Phrasing. Oxford: Oxford University Press, 2005.

Jun 2005 - Sun-Ah Jun (ed.). Prosodic Typology II: The Phonology of Intonation and Phrasing. Oxford: Oxford University Press, 2014.

Keijsper 1983 - C. E. K e ij s pe r. Comparing Dutch and Russian pitch contours // Russian Linguistics. 7. 1983. P. 101-154.

Kiss 1998 - K. E. K is s. Identificational Focus versus Information Focus // Language. 74. 1998. P. 245-273.

Kocharov et al. 2014 - D. K o c harov, P. S kre li n, N. Vols k a y a. F0 Declination Patterns in Russian // Speech and Computer, 16th International Conference Proceedings / A. Ronzhin, R. Potapova, D. Vlado (eds.). Dordrecht: Springer, 2014. P. 217 226.

Kocharov et al. 2015 - D. Ko c harov, N. Volsk ay a, P. S krelin. F0 Declination in Russian Revisited // Proceedings of the 18th International Congress of Phonetic Sciences / The Scottish Consortium for ICPhS 2015 (eds.). 2015.

Krifka 2008 - M. K r ifk a. Basic notions of information structure // Acta Linguistica Hungarica. 55. 2008. P. 243-276.

Ladd 1984 - D. R. L a d d. Declination: A Review and Some Hypotheses // Phonology Yearbook. 1. 1984. P. 53-74.

Ladd 2008 - D. R. L a d d. Intonational Phonology. Cambridge: Cambridge University Press, 2008. 
Levshina 2015 - N. Lev s h in a. How to do Linguistics with R. Data exploration and statistical analysis. Amsterdam: John Benjamins Publishing, 2015.

Makarova 2001 - V. M a k a rova. Perceptual correlates of sentence-type intonation in Russian and Japanese // Journal of Phonetics. 29. 2001. P. 137-154.

Makarova 2007 - V. M a k a rova. The Effect of Pitch Peak Alignment on Sentence Type Identification in Russian // Language and Speech. 50. 2007. P. 385-422.

Meyer, Mleinek 2006 - R. M e y e r, I. M 1 e i n e k. How prosody signals force and focus - A study of pitch accents in Russian yes-no questions // Journal of Pragmatics. 38. 2006. P. 1615-1635.

Odé 1989 - S. O dé. Russian intonation: a perceptual description. Amsterdam: Brill, 1989.

Odé 2005 - S. O d é. Neutralization or truncation? The perception of two Russian pitch accents on utterance-final syllables // Speech Communication. 47. 2005. P. 71-79.

Odé 2008 - S. O dé. Transcription of Russian intonation ToRI, an interactive research tool and learning module on the internet // Studies in Slavic and General Linguistics. 34. 2008. P. 431-449.

Pierrehumbert - J. Pi e r r e hu mbert. The phonology and phonetics of English intonation. Cambridge: MIT, 1980.

R Core Team 2018 - R C o r e T e a m. R: A language and environment for statistical computing. R Foundation for Statistical Computing. Vienna, 2018.

Rathcke 2006 - T. R a th c k e. A perceptual study on Russian questions and statements // Arbeitsberichte des Instituts für Phonetik und digitale Sprachverarbeitung der Universität Kiel (AIPUK). 37. 2006. P. 51-62.

Rathcke 2013 - T. R a th ck e. On the neutralizing status of truncation in intonation: A perception study of boundary tones in German and Russian // Journal of Phonetics. 41. 2013. P. 172-185.

Rathcke 2017 - T. R a th c k e. How Truncating Are 'Truncating Languages'? Evidence from Russian and German // Phonetica. 73. 2017. P. 194-228.

Repp 2019 - S. R e p p. The Prosody of Wh-exclamatives and Wh-questions in German: Speech Act Differences, Information Structure, and Sex of Speaker // Language and Speech. 63. 2019. P. 306-361.

Sosa 2003 - J. M. S o s a. Wh-questions in Spanish: meanings and configuration variability // Catalan Journal of Linguistics. 2. 2003. P. 229-247.

Svetozarova 1998 - N. S v e t o z a r o va. Intonation in Russian // Intonation systems: a survey of twenty languages / D. Hirst, A. Di Cristo (eds.). Cambridge: Cambridge University Press, 1998. P. 264-277.

Svetozarova, Kuosmanen 2003 - N. S v e to z a rova, A. K u o s m a n e n. Declination and finality in spontaneous and read speech in Russian // 15th International Congress of Phonetic Sciences / M. J. Solé, D. Recasens, J. Romero (eds.). 2003. P. 1297 1300.

ToRI-2008 - Transcription of Russian Intonation: a free interactive research tool and learning module by Cecilia Odé. URL: http://www.fon.hum.uva.nl/tori/ (дата обращения: 05.12.2019).

Zimmermann, Féry 2010 - M. Z i m m e r m a n n, C. F éry (eds.). Information structure: Theoretical, typological, and experimental perspectives. Oxford: Oxford University Press, 2010. 


\author{
Pavel V. Duryagin \\ Ca' Foscari University of Venice \\ (Venice, Italy) \\ pavel.duryagin@unive.it
}

\title{
RUSSIAN WH-QUESTION INTONATION: EXPERIMENTAL DATA ON SOME SOURCES OF VARIATION
}

The paper presents the results of an experimental study of prosody in Russian whquestions. The data were elicited by means of a dialogue reading task performed by 20 native speakers of Standard Russian. The results generally corroborate existing reports on the variability of pitch contours, making it possible to determine the basic types of tonal configurations and propose a preliminary phonological interpretation for these contours within the Autosegmental metrical model of intonation. Four different configurations of accents were found in the data: on the one hand, three "falling" contours containing a low edge tone preceded by different combinations of prenuclear accents; on the other hand, a single "rising" contour containing a high edge tone. In addition, effects of two factors on the choice of question tune were tested: focus type and presence of phrase-initial particle. Both effects were found to be significant. While contrastive focus restricted the use of the high edge tone configuration (to a varying extent, depending on the syntactic role of the word in focus), the rising tune was more likely to be chosen in the presence of the particle.

Keywords: phonetics, intonation, wh-question, variability, focus

\section{References}

Arvaniti, A., \& Baltazani, M. (2005). Intonational analysis and prosodic annotation of Greek spoken corpora. In Sun-Ah Jun (Ed.), Prosodic typology: The phonology of intonation and phrasing (pp. 84-117). Oxford: Oxford University Press.

Arvaniti, A., \& Ladd, D. R. (2009). Greek wh-questions and the phonology of intonation. Phonology, 26, 43-74.

Baltazani, M., Gryllia, S., \& Arvaniti, A. (2019). The intonation and pragmatics of Greek wh-questions. Language and speech, 63(1), 56-94.

Bates, D., Maechler, M., Bolker, B., \& Walker, S. (2015). Fitting linear mixedeffects models using lme4. Journal of statistical software, 67(1), 1-48.

Baumann, S. (2012). The intonation of givenness: evidence from German. Berlin: De Gruyter.

Baumann, S., Becker, J., Grice, M., \& Mücke, D. (2007). Tonal and articulatory marking of focus in German. In J. Trouvain, \& W. J. Barry (Eds.), $16^{\text {th }}$ International congress of phonetic sciences (pp. 1029-1032). Saarbrücken: Univ. des Saarlandes.

Beckman, M. E., \& Pierrehumbert, J. (1986). Intonational structure in Japanese and English. Phonology yearbook, 3, 15-70.

Beckman, M. E., Hirschberg, J., \& Shattuck-Hufnagel, S. (2005). The Original ToBI system and the evolution of the ToBI framework. In Sun-Ah Jun (Ed.), Prosodic typology: the phonology of intonation and phrasing (pp. 9-54). Oxford: Oxford University Press.

Beziaeva, E. G. (2002). Semantika kommunikativnogo urovnia zvuchashchego yazyka. Moscow: Izd-vo Mosk. un-ta. 
Bocci, G., Bianchi, V., \& Cruschina, S. (2021). Focus in wh-questions. Natural Language and Linguistic Theory, 39, 405-455.

Braun, B., \& Biezma, M. (2019). Prenuclear L*+H activates alternatives for the accented word. Frontiers in psychology, 10, 1993.

Breen, M., Fedorenko, E., Wagner, M., \& Gibson, E. (2010). Acoustic correlates of information structure. Language and cognitive processes, 25, 1044-1098.

Bryzgunova, E. A. (1963). Prakticheskaia fonetika i intonatsiia russkogo yazyka. Moscow: Izd-vo Mosk. un-ta.

Bryzgunova, E. A. (1980). Intonatsiia. In N. Yu. Shvedova (Ed.), Russkaia grammatika. T. 1: Fonetika, fonologiia, udarenie, intonatsiia, slovoobrazovanie, morfologiia. Moscow: Nauka.

Bryzgunova, E. A. (1980a). Sredstva vyrazheniia neizvestnogo v voprose (vzaimodeistvie leksiki, konteksta i intonatsii). In N. Yu. Shvedova (Ed.), Russkaia grammatika. T. 2: Sintaksis. Moscow: Nauka.

Büring, D. (2007). Semantics, intonation, and information structure. In G. Ramchand, \& C. Reiss (Eds.), The Oxford handbook of linguistic interfaces (pp. 445-474). Oxford: Oxford University Press.

Calhoun, S. (2010). The centrality of metrical structure in signaling information structure: a probabilistic perspective. Language, $86,1-42$.

Chen, A. (2012). Shaping the intonation of WH-questions: information structure and beyond. In J. P. de Ruiter (Ed.), Questions: formal, functional and interactional perspectives (pp. 146-164) Cambridge: Cambridge University Press.

Chodroff, E., \& Cole, J. (2018). Information structure, affect, and prenuclear prominence in American English. In B. Yegnanarayana (Ed.), Proceedings of Interspeech 2018 (pp. 1848-1852). Retrieved from https://www.isca-speech.org/archive/Interspeech_2018/

Féry, C., \& Ishihara, S. (Eds.). (2016). The Oxford handbook of information structure. Oxford: Oxford University Press.

Féry, C., \& Kügler, F. (2008). Pitch accent scaling on given, new and focused constituents in German. Journal of Phonetics, 36, 680-703.

Fox, J., \& Weisberg, S. (2019). An $\{R\}$ companion to applied regression ( $\left.3^{\text {rd }} \mathrm{ed}.\right)$. Thousand Oaks: SAGE Publishing.

Fuzheron, I. (1997). O nekotorykh osobennostiakh russkikh sochinitel'nykh soiuzov. Soiuzy $i$ i $a$, soiuzy a i no. In T. M. Nikolaeva (Ed.), Slavianskie sochinitel'nye soiuzy (pp. 25-35). Moscow: In-t slavianovedeniia RAN.

Grice, M., Baumann, S., \& Benzmüller, R. (2005). German intonation in autosegmental-metrical phonology. In Sun-Ah Jun (Ed.), Prosodic typology: the phonology of intonation and phrasing (pp. 55-83). Oxford: Oxford University Press.

Grice, M., Ladd, D. R., \& Arvaniti, A. (2000). On the place of phrase accents in intonational phonology. Phonology, 17, 143-185.

Gryllia, S., Baltazani, M., \& Arvaniti, A. (2018). The role of pragmatics and politeness in explaining prosodic variability. In K. Klessa, J. Bachan, A. Wagner, M. Karpiński, \& D. Śledziński (Eds.), Proceedings of the $9^{\text {th }}$ International conference on speech prosody (pp. 158-162). Poznan: Peter Lang.

Gryllia, S., Baltazani, M., \& Arvaniti, A. (2019). Evidence for the compositionality of tunes and intonational meaning. In S. Calhoun, P. Escudero, M. Tabain, \& P. Warren (Eds.), Proceedings of the $19^{\text {th }}$ International congress of phonetic sciences (pp. 2841-2845). Melbourne: Australasian Speech Science and Technology Association Inc. 
Gussenhoven, C. (2004). The Phonology of tone and intonation. Cambridge: Cambridge University Press.

Gussenhoven, C. (2008). Types of focus in English. In C. Lee, M. Gordon, \& D. Büring (Eds.), Topic and focus (pp. 83-100). Dordrecht: Springer.

Haan, J. (2001). Speaking of questions: an exploration of Dutch question intonation. Utrecht: LOT.

Hedberg, N., \& Sosa, J. M. (2002). The prosody of questions in natural discourse. In B. Bel, \& I. Marlien (Eds.), Speech prosody 2002 (pp. 375-378). Aix-en-Provence: Laboratoire Parole et Langage.

Hedberg, N., Sosa, J. M., \& Fadden, L. (2004). Meanings and configurations of questions in English. In B. Bel, \& I. Marlien (Eds.), Speech prosody 2004 (pp. 309-312). Nara: [s.n.].

Hirschberg, J. (1989). Distinguishing questions by contour in speech recognition tasks. In Speech and natural language: proceedings of a workshop (pp. 22-33). Massachusetts: Morgan Kaufmann Publishers.

Hirschberg, J. (2000). A corpus-based approach to the study of speaking style. In M. Horne (Ed.), Prosody: theory and experiment (pp. 335-350). Dordrecht: Springer.

Igarashi, Y. (2006). Intonational patterns in Russian interrogatives - phonetic analyses and phonological interpretations. In Y. Kawaguchi, I. Fónagy, \& T. Moriguchi (Eds.), Prosody and syntax: cross-linguistic perspectives (pp. 175-196). Amsterdam: John Benjamins Publishing.

Igarashi, Y. (2008). Russian interrogatives and intonational categories. In A. Steube (Ed.), The discourse potential of underspecified structures (pp. 227-269). Berlin: De Gruyter.

Igarasi, I. (2002). Tak nazyvaemaia «neitralizatsiia intonatsii» - fonologicheskoe opisanie russkoi intonatsii. Biulleten' Yaponskoi assotsiatsii rusistov, 34, 15-21.

Keijsper, C. E. (1983). Comparing Dutch and Russian pitch contours. Russian Linguistics, 7, 101-154.

Kiss, K. E. (1998). Identificational focus versus information focus. Language, 74, $245-273$.

Kocharov, D., Skrelin, P., \& Volskaya, N. (2014). F0 declination patterns in Russian. In A. Ronzhin, R. Potapova, \& D. Vlado (Eds.), Speech and computer, $16^{\text {th }}$ International conference proceedings (pp. 217-226). Dordrecht: Springer.

Kocharov, D., Volskaya, N., \& Skrelin, P. (2015). F0 declination in Russian revisited. In M. Wolters, J. Livingstone, B. Beattie, R. Smith, M. MacMahon, J. Stuart-Smith, \& J. M. Scobbie (Eds.), Proceedings of the $18^{\text {th }}$ International congress of phonetic sciences. Glasgow: University of Glasgow. Retrieved from https://www.researchgate.net/ publication/283908493_F0_DECLINATION_IN_RUSSIAN_REVISITED

Kodzasov, S. V. (1985). Intonatsiia voprositel'nykh predlozhenii: forma i funktsii. In A. S. Narin'iani (Ed.), Dialogovoe vzaimodeistvie i predstavlenie znanii (pp. 48-63). Novosibirsk: VTs SO AN SSSR.

Kodzasov, S. V. (1996). Kombinatornaia model' frazovoi prosodii. In T. M. Nikolaeva (Ed.), Prosodicheskii stroi russkoi rechi (pp. 85-121). Moscow: In-t rus. iaz. RAN.

Kodzasov, S. V. (2009). Issledovaniia v oblasti russkoi prosodii. Moscow: Yazyki slavianskikh kul'tur.

Krifka, M. (2008). Basic notions of information structure. Acta Linguistica Hungarica, 55, 243-276. 
Ladd, D. R. (1984). Declination: a review and some hypotheses. Phonology yearbook, 1, 53-74.

Ladd, D. R. (2008). Intonational phonology. Cambridge: Cambridge University Press.

Levshina, N. (2015). How to do linguistics with R. Data exploration and statistical analysis. Amsterdam: John Benjamins Publishing.

Makarova, V. (2001). Perceptual correlates of sentence-type intonation in Russian and Japanese. Journal of Phonetics, 29, 137-154.

Makarova, V. (2007). The effect of pitch peak alignment on sentence type identification in Russian. Language and speech, 50, 385-422.

Meyer, R., \& Mleinek, I. (2006). How prosody signals force and focus - A study of pitch accents in Russian yes-no questions. Journal of Pragmatics, 38, 1615-1635.

Nikolaeva, T. M. (1982). Semantika aktsentnogo vydeleniia. Moscow: Nauka.

Nikolaeva, T. M. (1997). Sochinitel'nye soiuzy $a$, no, $i$ : istoriia, skhodstva i razlichiia. In T. M. Nikolaeva (Ed.), Slavianskie sochinitel'nye soiuzy (pp. 3-24). Moscow: In-t slavianovedeniia RAN.

Odé, S. (1989). Russian intonation: a perceptual description. Amsterdam: Brill.

Odé, S. (2005). Neutralization or truncation? The perception of two Russian pitch accents on utterance-final syllables. Speech communication, 47, 71-79.

Ode, S. (2007). Zametki o poniatii tonal'nyi aktsent na primere russkogo yazyka. In R. F. Kasatkina (Ed.), Problemy fonetiki (pp. 237-249). Moscow: Nauka.

Odé, S. (2008). Transcription of Russian intonation ToRI, an interactive research tool and learning module on the internet. Studies in Slavic and general linguistics, 34, 431-449.

Pierrehumbert, J. (1980). The phonology and phonetics of English intonation. Cambridge: MIT.

Podlesskaia, V. I. (2018). «A u nas v kvartire gaz! A u vas?»: konstruktsii s soiuzom A po dannym prosodicheski razmechennogo korpusa. In V. P. Selegei (Ed.), Komp'iuternaia lingvistika $i$ intellektual'nye tekhnologii: Po materialam ezhegodnoi mezhdunarodnoi konferentsii «Dialog» (pp. 601-618). Moscow: Izdatel'skii tsentr RGGU.

Rathcke, T. (2006). A perceptual study on Russian questions and statements. Arbeitsberichte des Instituts für Phonetik und digitale Sprachverarbeitung der Universität Kiel, 37, 51-62.

Rathcke, T. (2013). On the neutralizing status of truncation in intonation: a perception study of boundary tones in German and Russian. Journal of phonetics, 41, 172-185.

Rathcke, T. (2017). How truncating are 'truncating languages'? Evidence from Russian and German. Phonetica, 73, 194-228.

Repp, S. (2019). The Prosody of wh-exclamatives and wh-questions in German: speech act differences, information structure, and sex of speaker. Language and speech, 63, 306-361.

Shkapa, M. V. (2013). Kleft v irlandskom yazyke: k tipologii klefta i teticheskikh predlozhenii. Voprosy jazykoznanija, 5, 89-105.

Sosa, J. M. (2003). Wh-questions in Spanish: meanings and configuration variability. Catalan journal of linguistics, 2, 229-247.

Sun-Ah Jun (Ed.). (2005). Prosodic typology: the phonology of intonation and phrasing. Oxford: Oxford University Press.

Sun-Ah Jun (Ed.). (2014). Prosodic typology II: the phonology of intonation and phrasing. Oxford: Oxford University Press.

Svetozarova, N. (1998). Intonation in Russian. In D. Hirst, \& A. Di Cristo (Eds.), Intonation systems: a survey of twenty languages (pp. 264-277). Cambridge: Cambridge University Press. 
Svetozarova, N., \& Kuosmanen, A. (2003). Declination and finality in spontaneous and read speech in Russian. In M. J. Solé, D. Recasens, \& J. Romero (Eds.), $15^{\text {th }}$ International congress of phonetic sciences (pp. 1297-1300). Barcelona: Causal Productions.

Transcription of Russian Intonation: a free interactive research tool and learning module by Cecilia Odé. Retrieved from http://www.fon.hum.uva.nl/tori/

Yanko, T. E. (2008). Intonatsionnye strategii russkoi rechi v sopostavitel'nom aspekte. Moscow: Yazyki slavianskikh kul'tur.

Yokoyama, O. (2003). Neitral'naia i neneitral'naia intonatsiia v russkom yazyke: avtosegmentnaia interpretatsiia sistemy intonatsionnykh konstruktsii. Voprosy jazykoznanija, 5, 99-122.

Zaliznyak, A., \& Mikaelyan, I. (2018). Soiuz a. In O. Yu. In'kova (Ed.), Semantika konnektorov: kontrastivnoe issledovanie (pp. 24-79). Moscow: Torus Press.

Zaliznyak, A., \& Mikaelyan, I. (2018a). Russkoe $a$ : opyt integral'nogo opisaniia. Russian Linguistics, 42, 321-344.

Zimmermann, M., \& Féry, C. (Eds.). (2010). Information structure: Theoretical, typological, and experimental perspectives. Oxford: Oxford University Press.

Received on August 6, 2020 